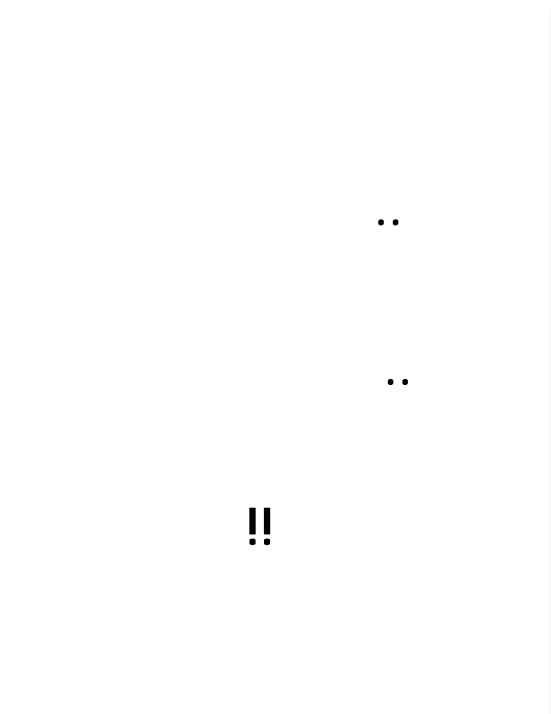

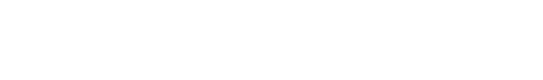
الثموب(") وهي تتحرد، وتسبل ناكوا، والثالرخ ذاله لا يرهم من يسلال $\square$ الاهنمل بنالك الذاكوة
سجل ذاكرة العالم(1)

ودوره في نشر التراث

الوثائقى (التجربة المصرية)

د. إصل عمر مطاف لكستاذ الوثئ لمسلفد كلة الآلب -جلة الفلهرة 


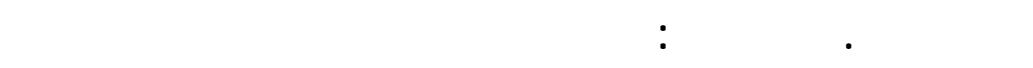

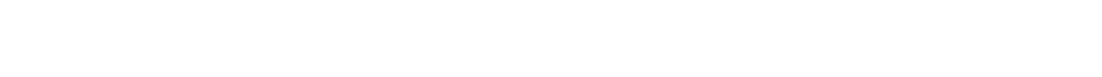

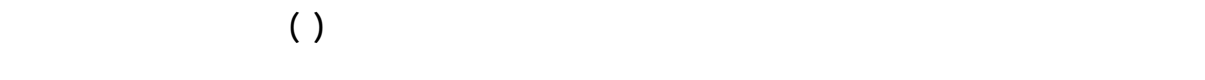

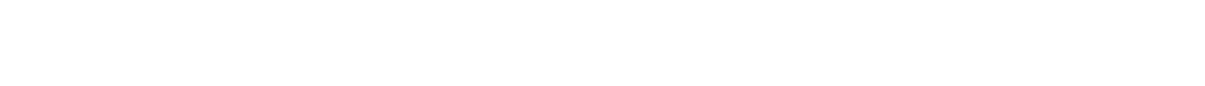

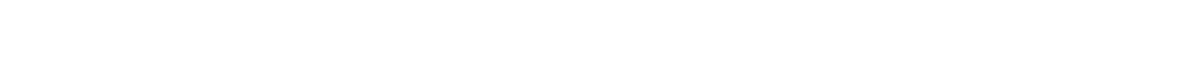

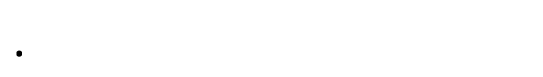

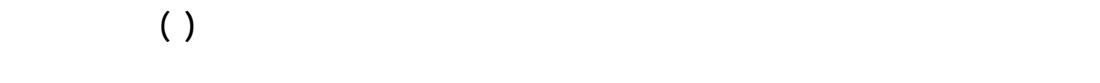

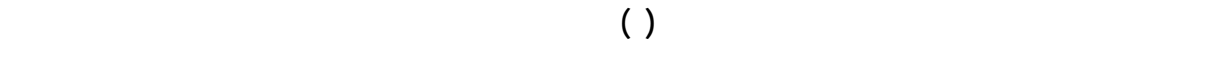

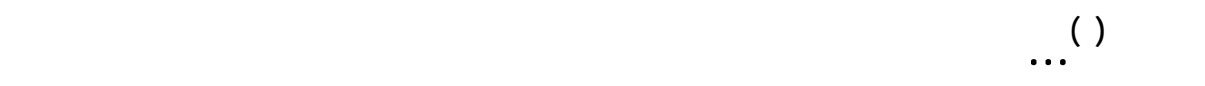

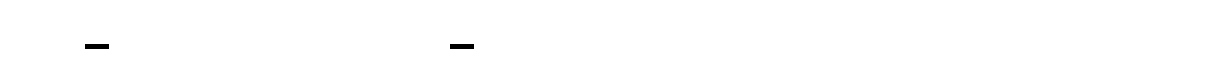

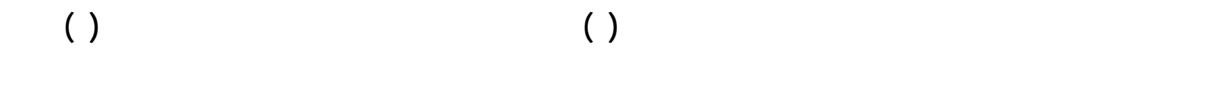

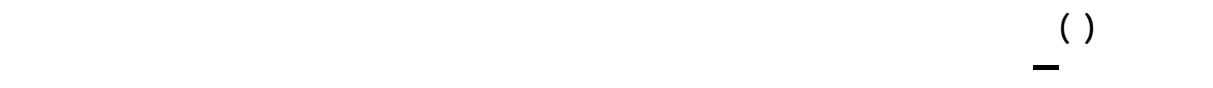

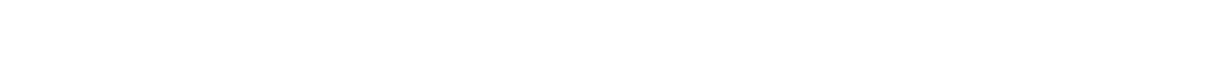

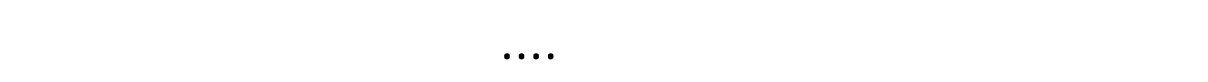

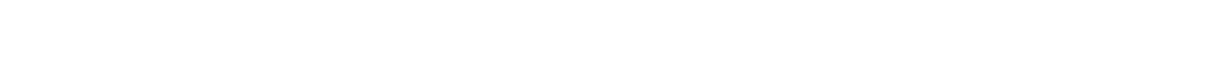

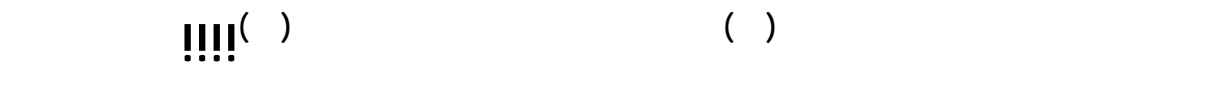

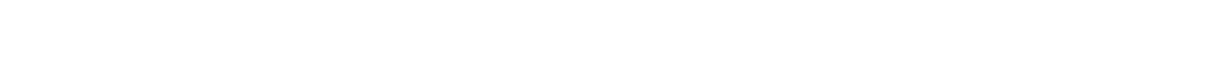

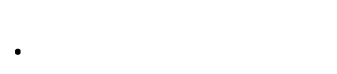

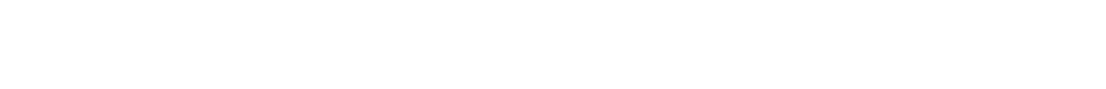
ال]ضر.

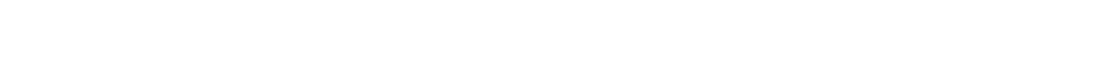

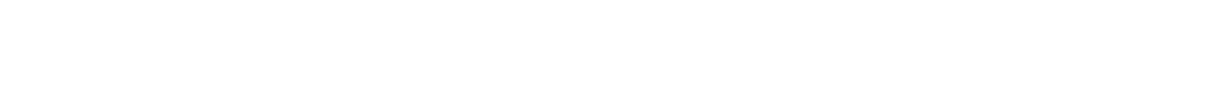

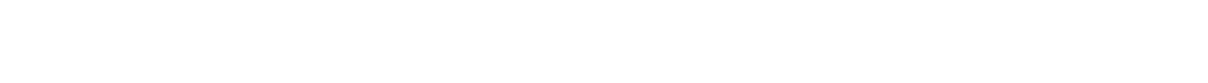




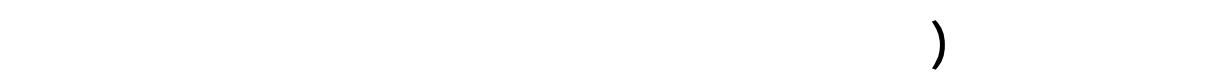

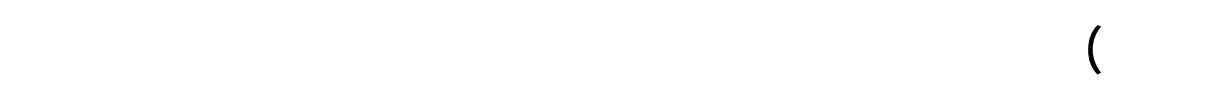

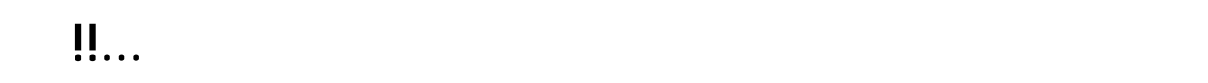

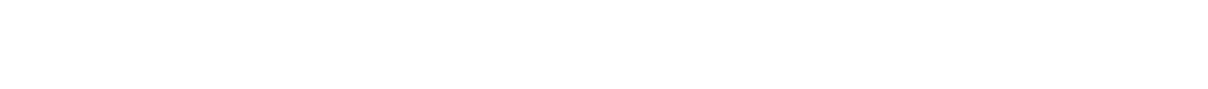

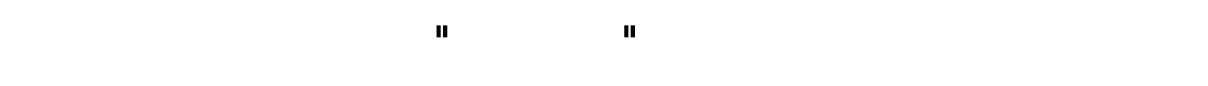

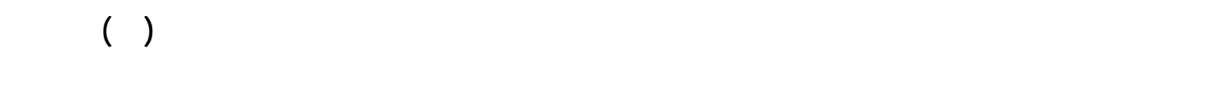

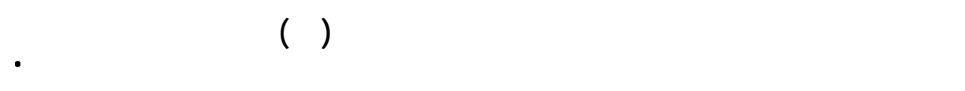

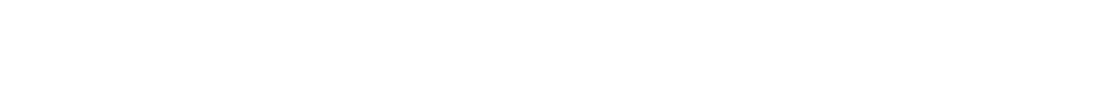

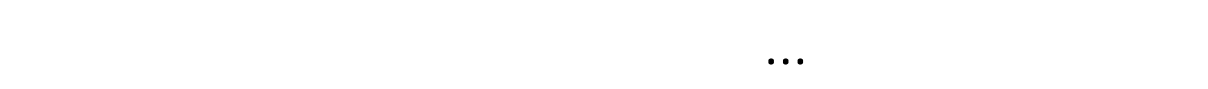

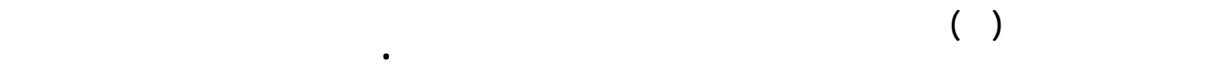

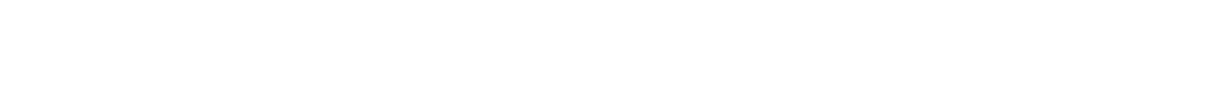

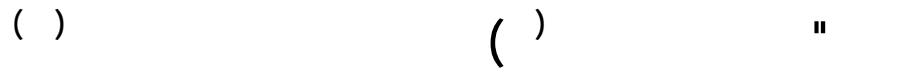

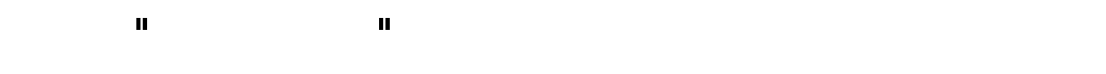

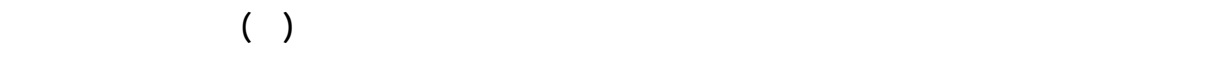

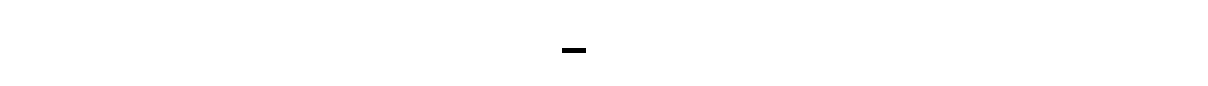

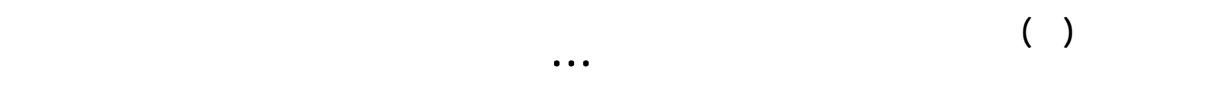

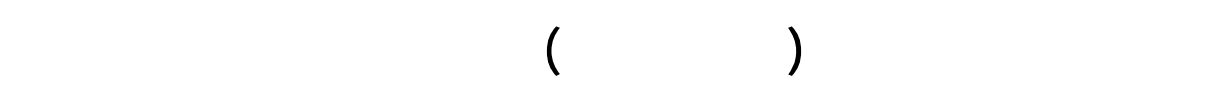

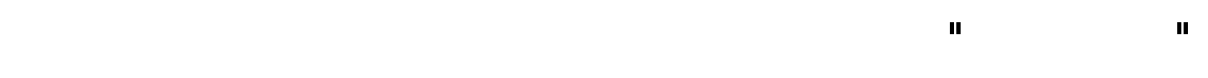

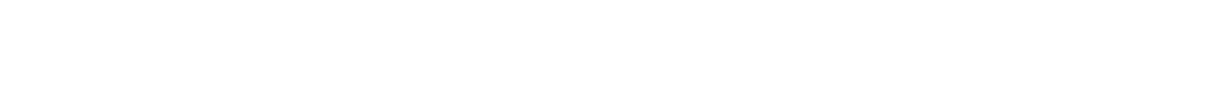

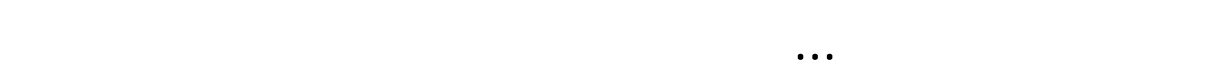

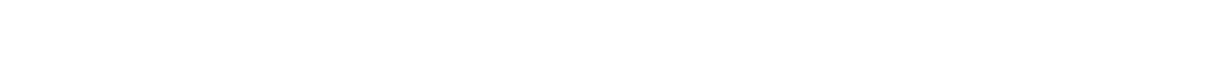

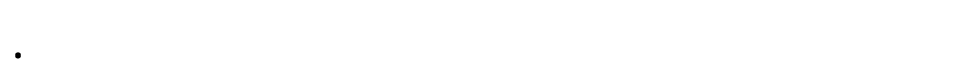




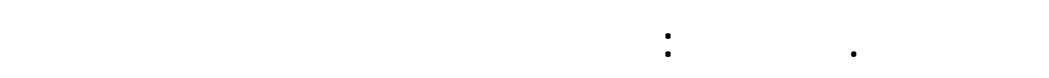

\section{ويق السؤل}

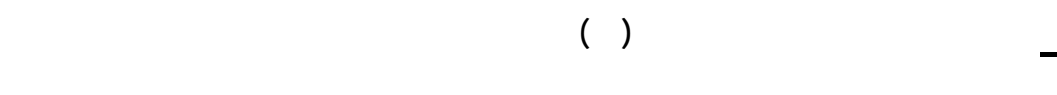

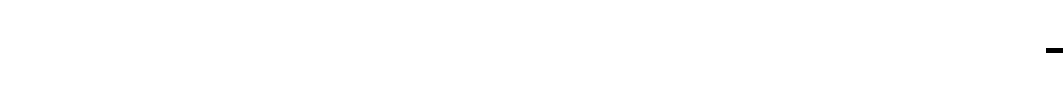

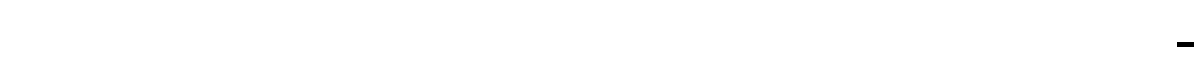

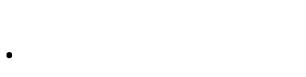

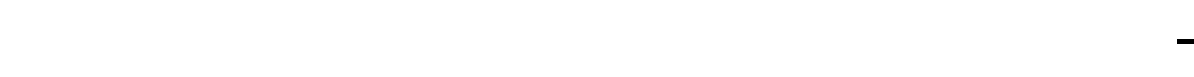
بالوثلئفيك

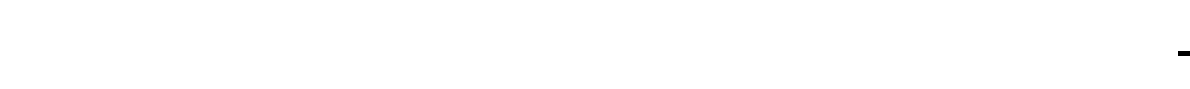

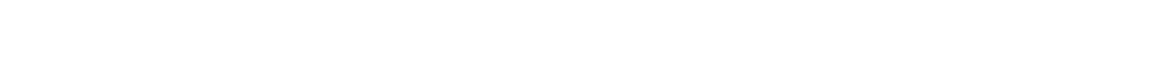

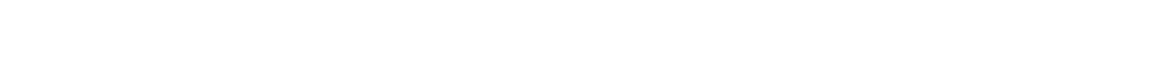

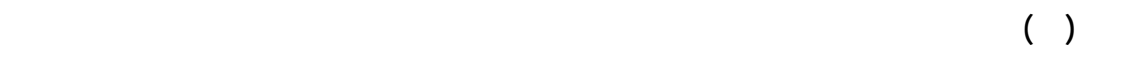

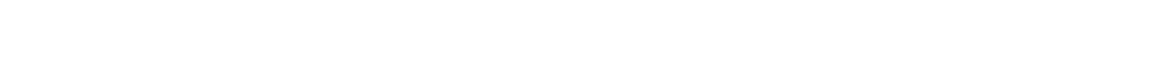

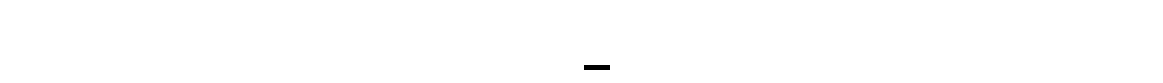

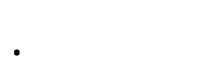

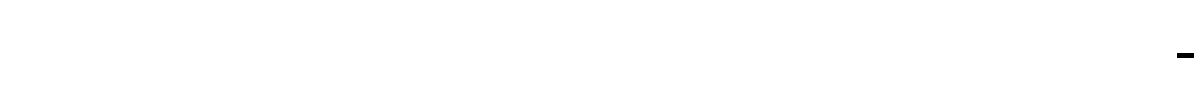

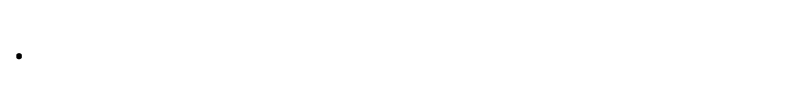

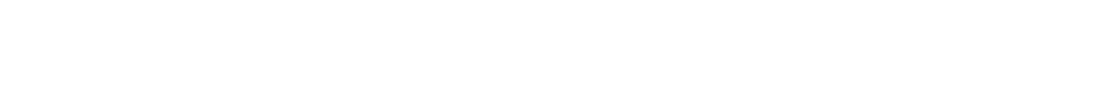

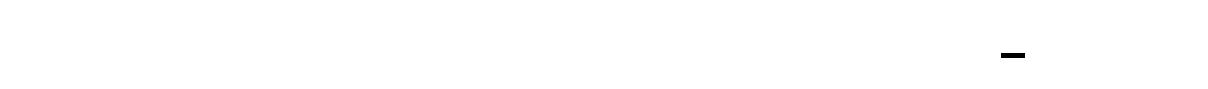

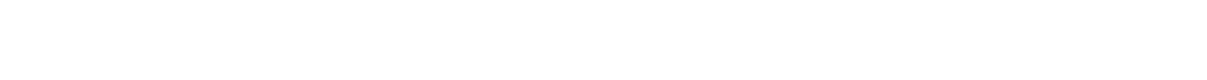

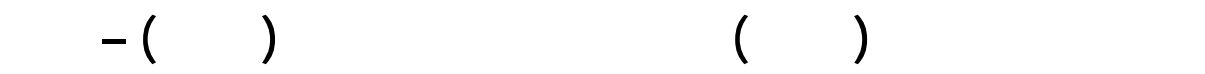

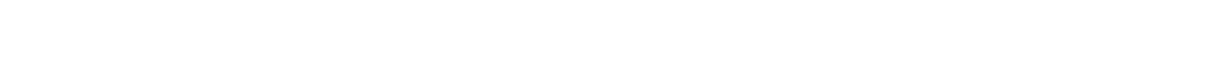
هذا المتلمجسأليا لتهقى: 


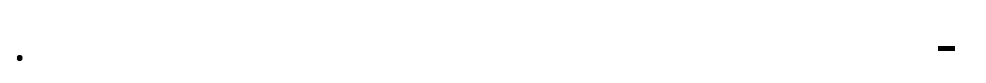

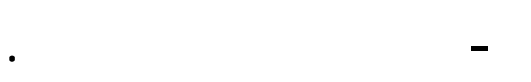

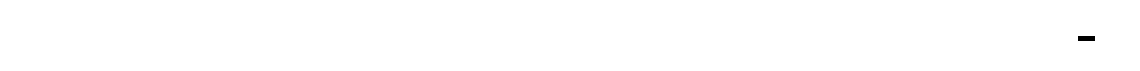
التسجلى.

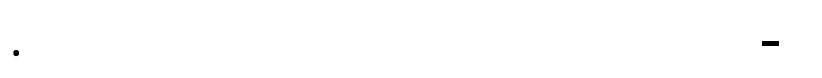

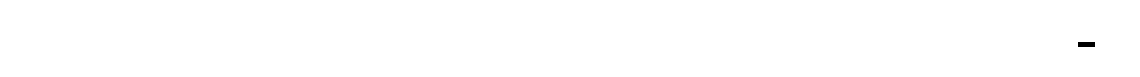

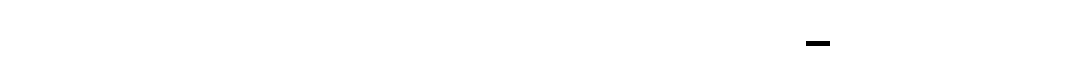
الها لبانبر

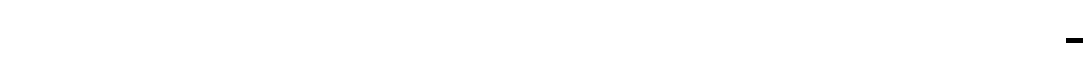

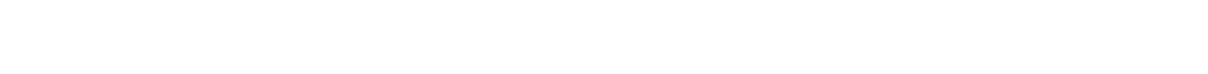
لذاك، ودئم التشربك لولية ذلت الملة.

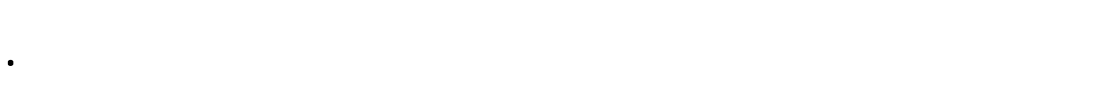

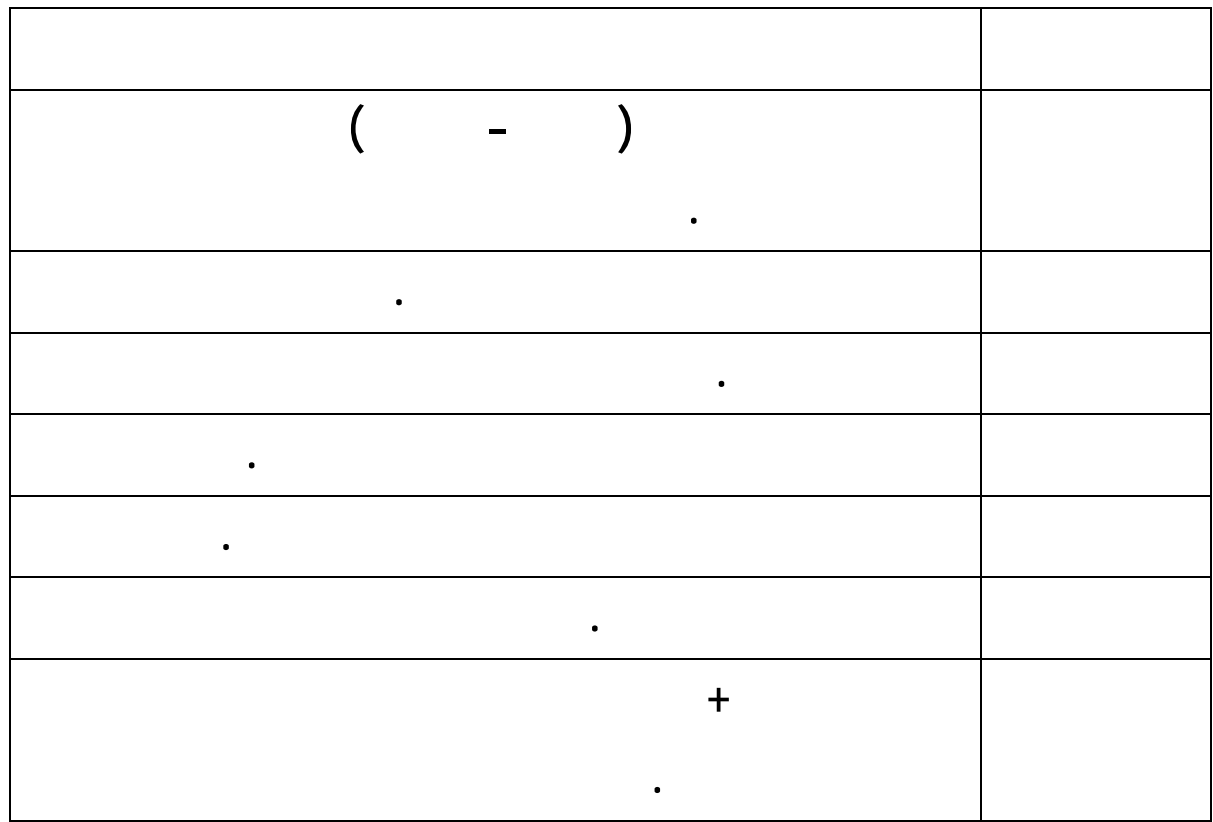




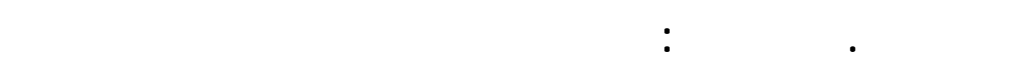

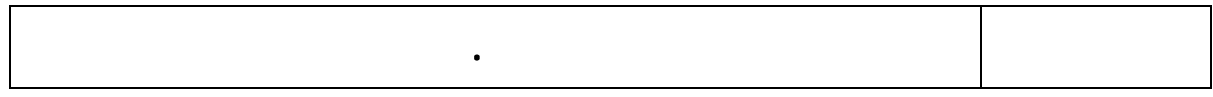

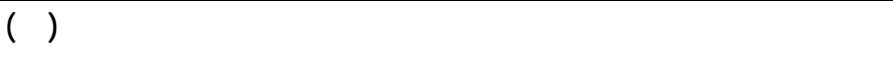

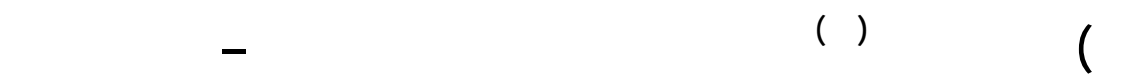

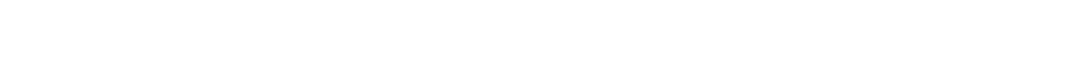

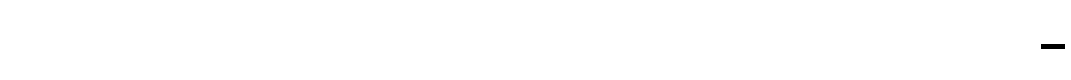

الوثالي.

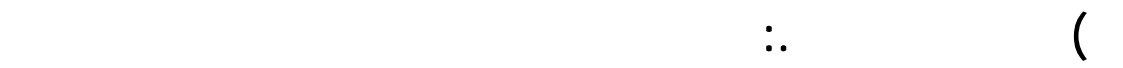

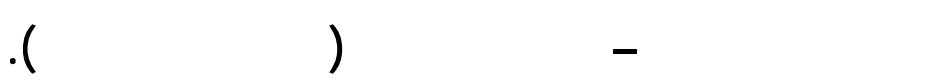

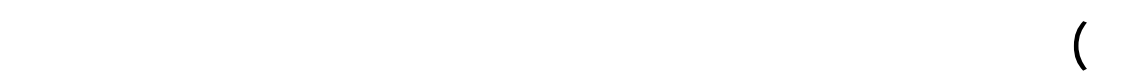

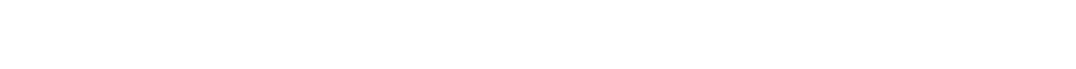

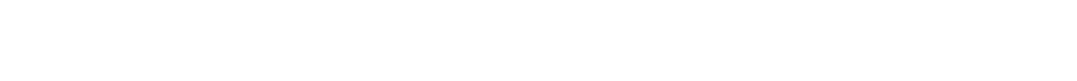

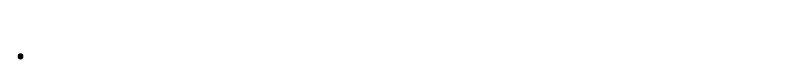

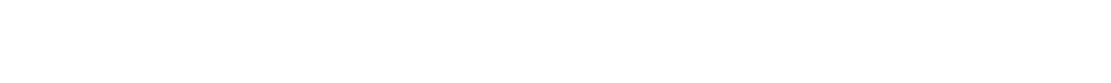

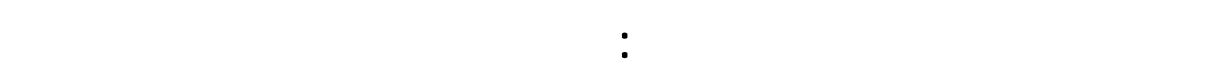

السطلات الساقيك

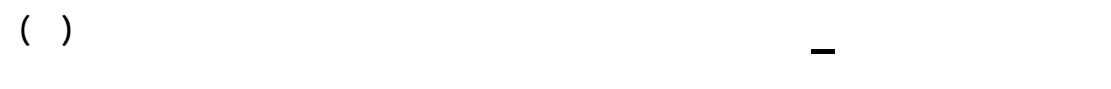

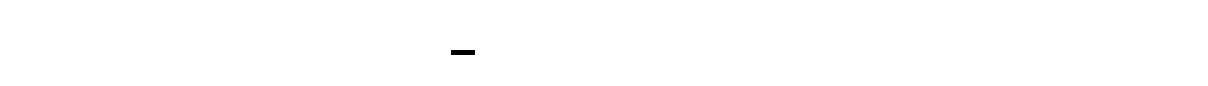

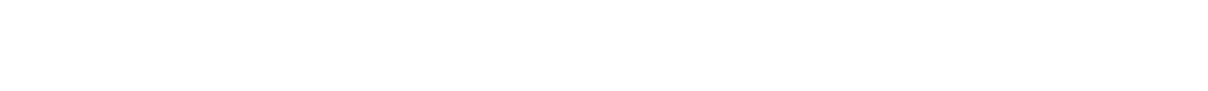

إلعاليمايلي:

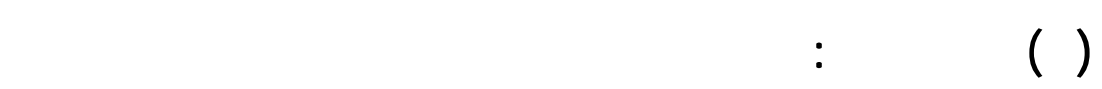

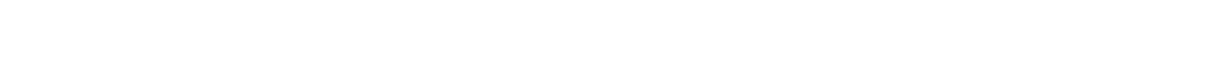

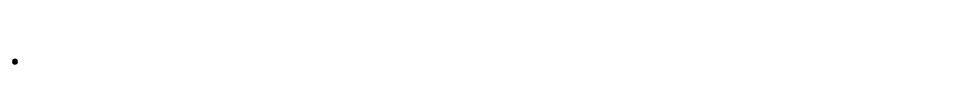


E I

لرهزنة (لمدد لهنالع - I 1 - م)

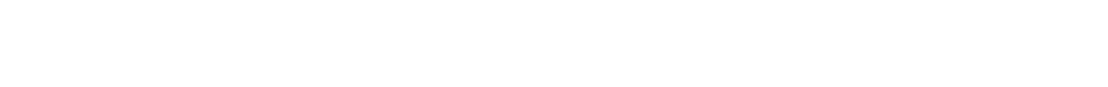

تلاية:

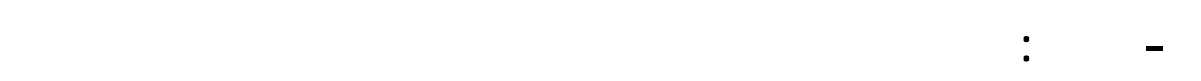

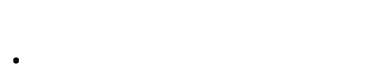

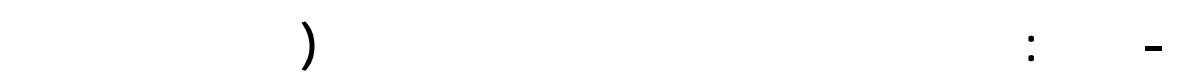

مهالة الشرق الأوبط).

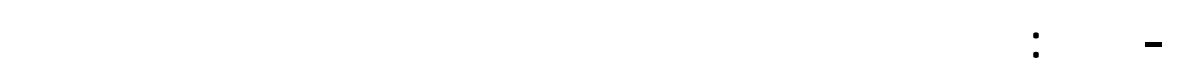

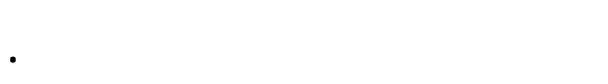

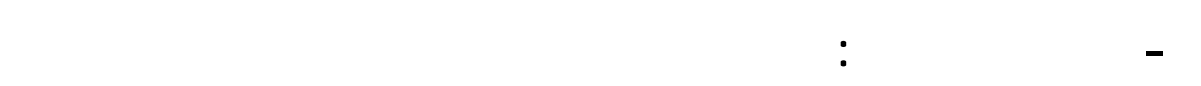

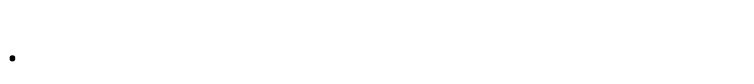

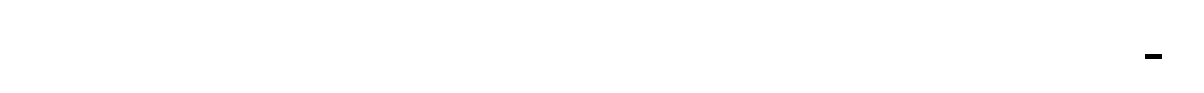

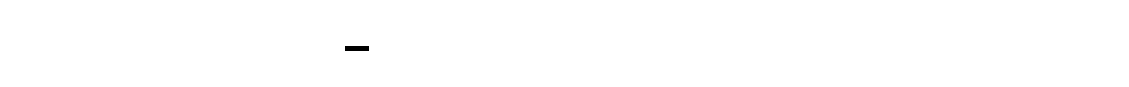

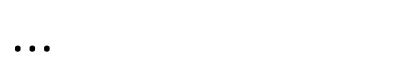

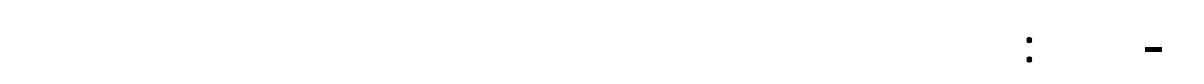

قيد الصبة.

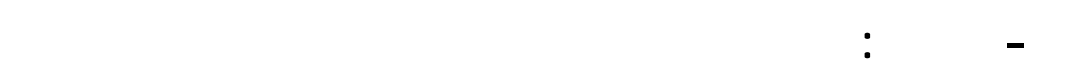

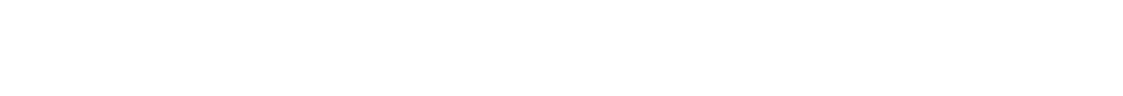

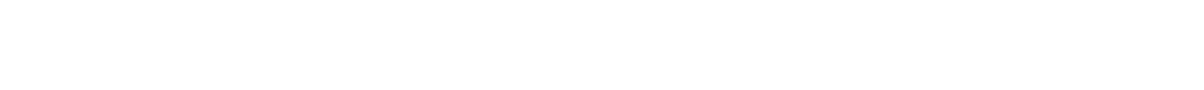

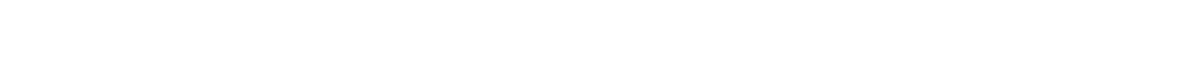

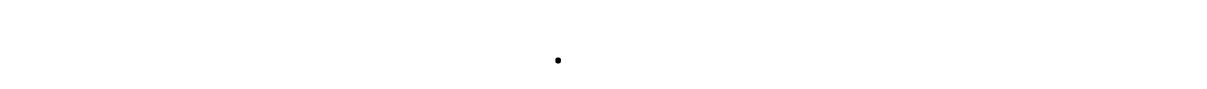

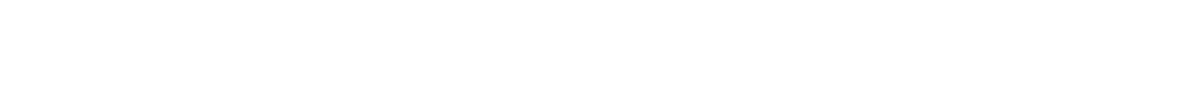

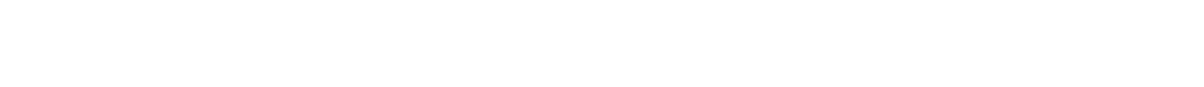




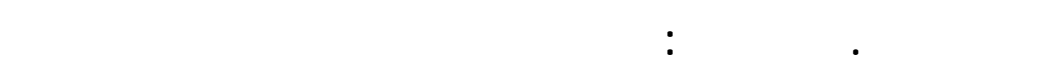

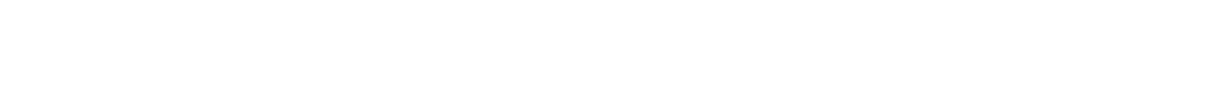

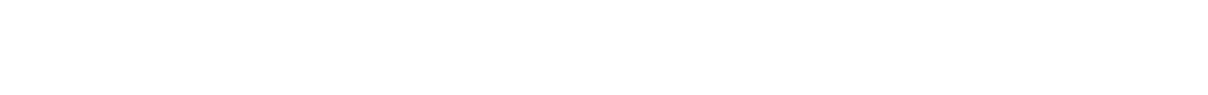

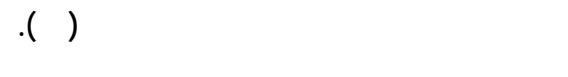

$$
\text { التجربة المصرية }
$$

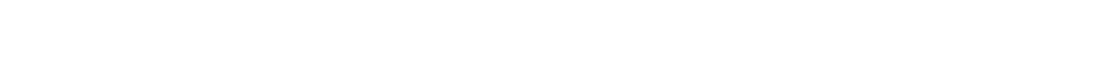

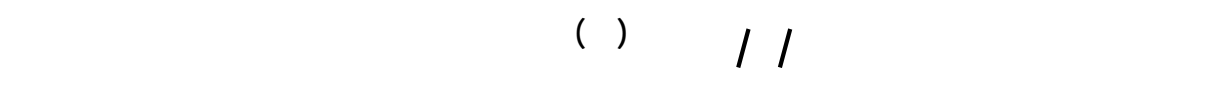

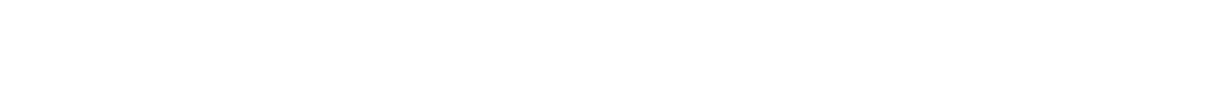

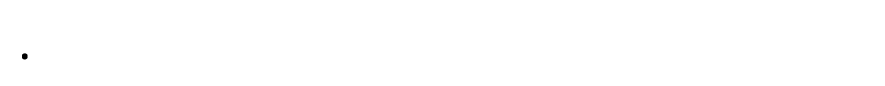

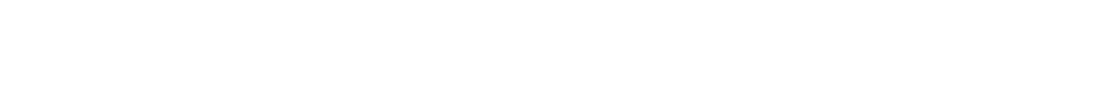

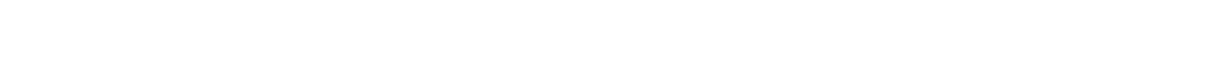
(17)

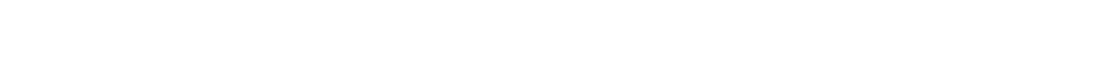

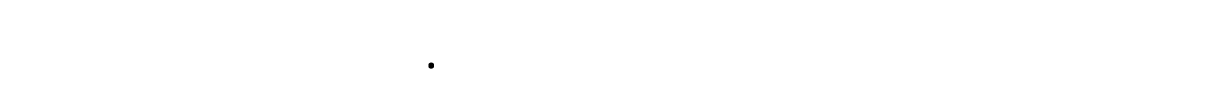

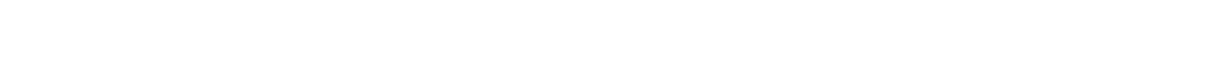

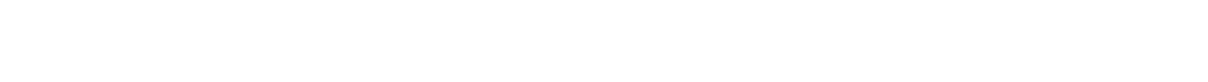

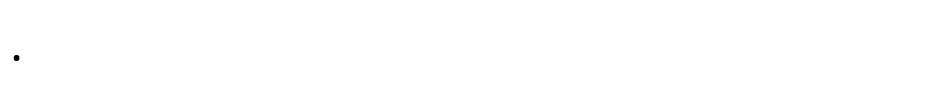

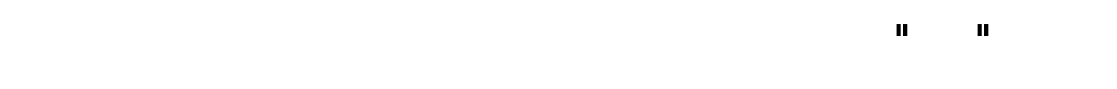

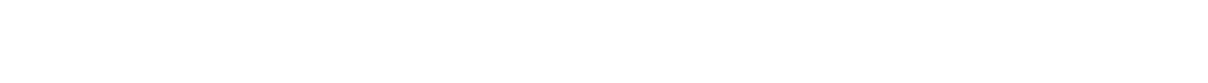

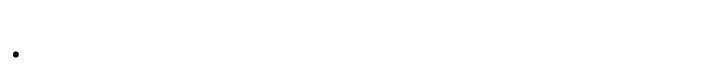


Eוr

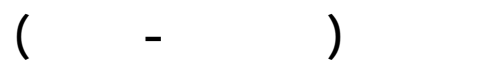

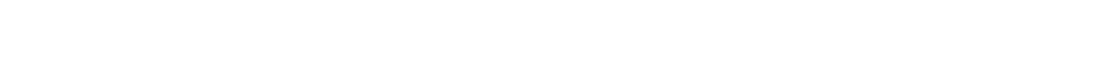

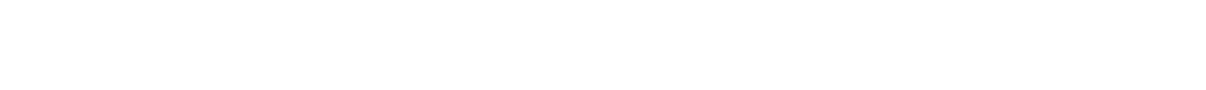

المة الرئية باليس.

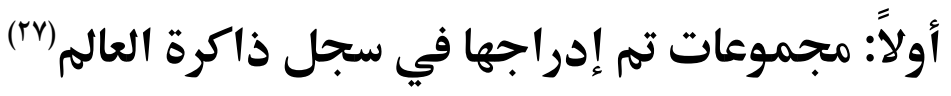

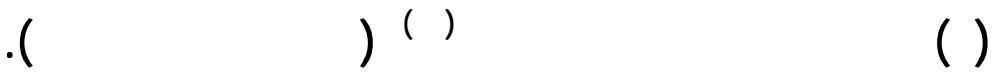

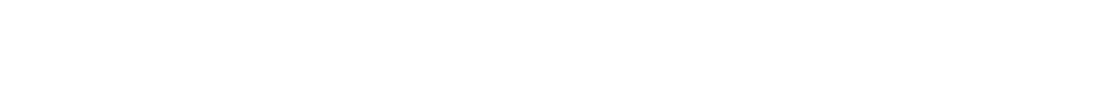

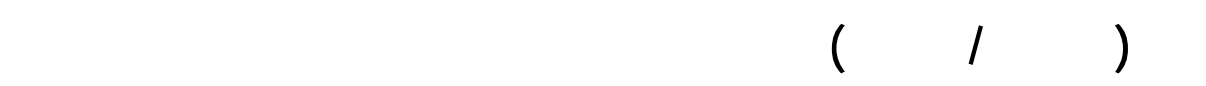

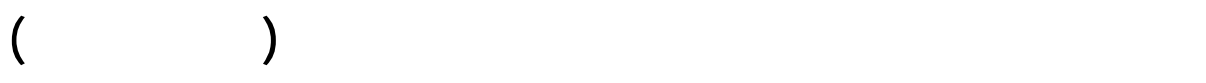

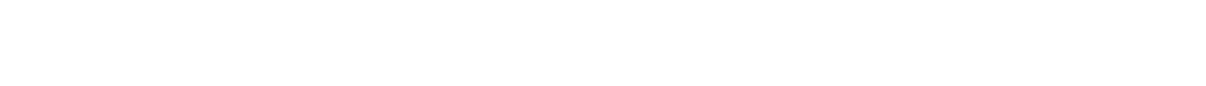

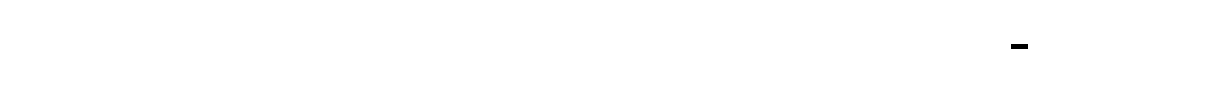

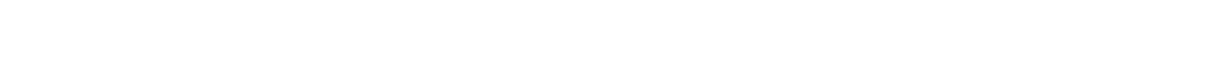
قوصن وغ فما.

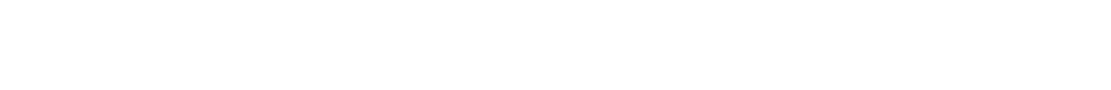

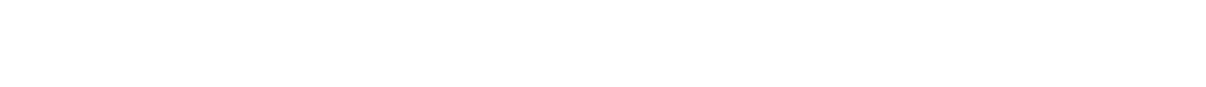

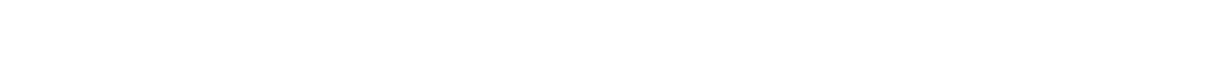

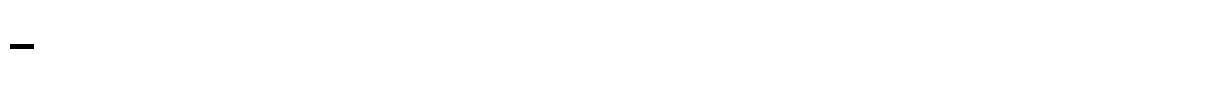

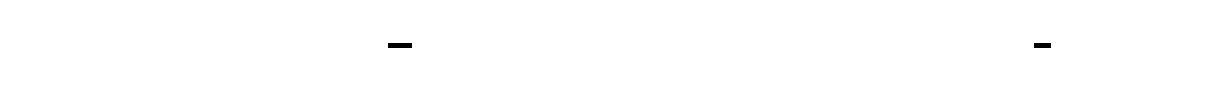
الوثأق للالة:

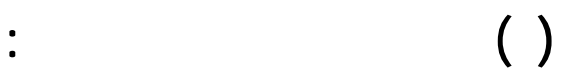

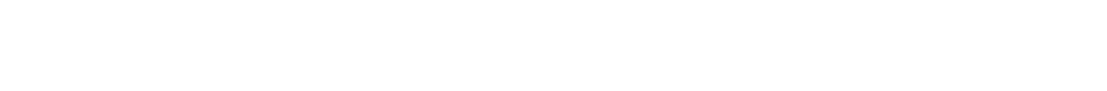

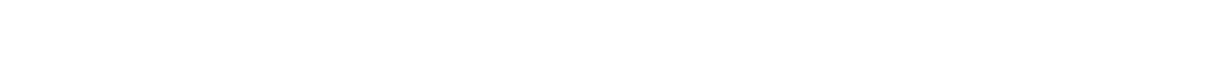

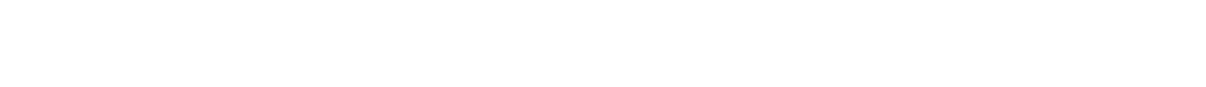




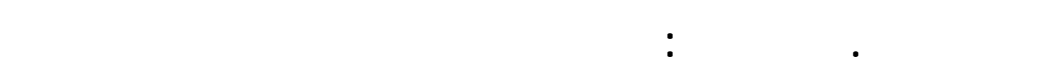

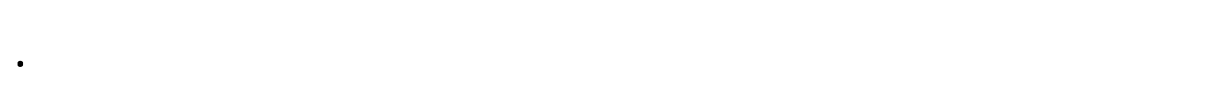

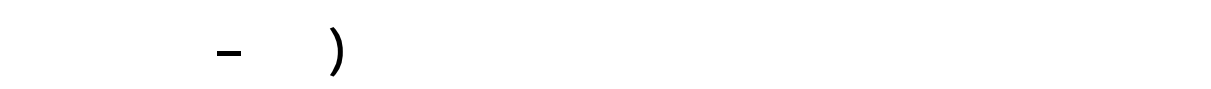
- إلرن).

$$
\text { (انانيا: ترشيحات لم يوافق على إدراجها في السجل العالمي: }
$$

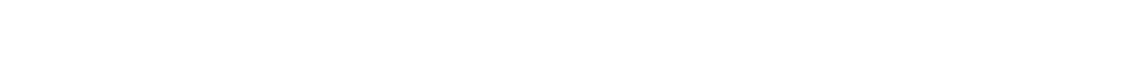

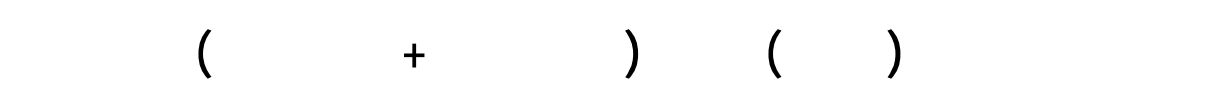

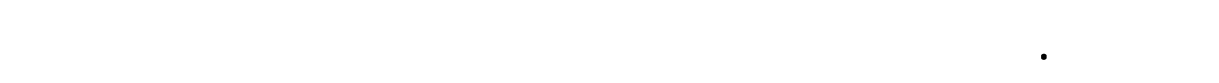

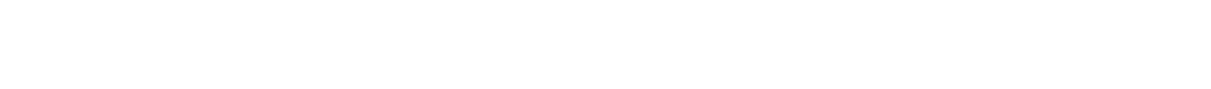

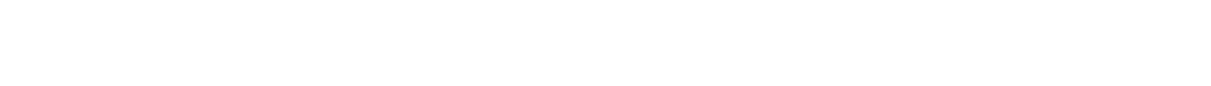

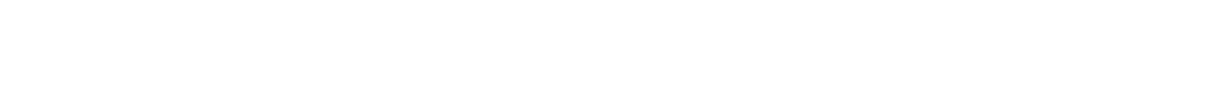

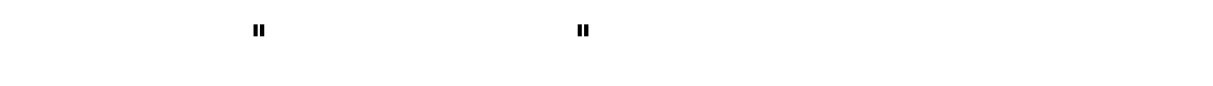

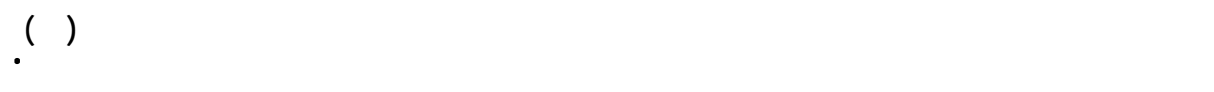

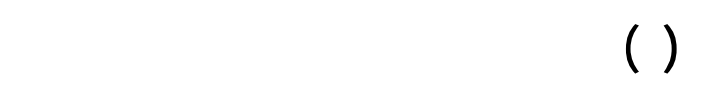

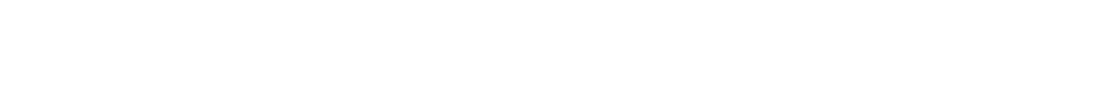

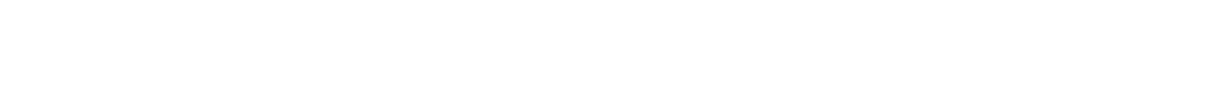

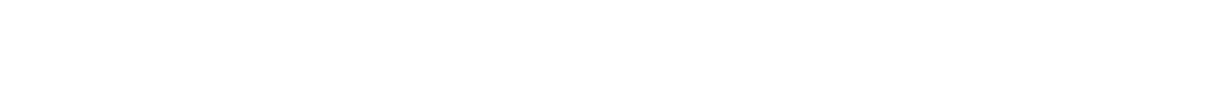

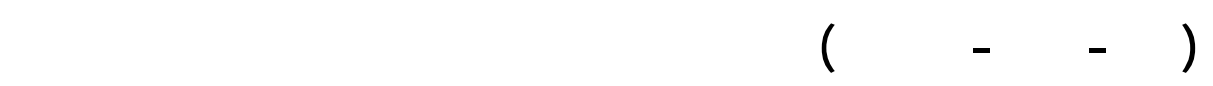

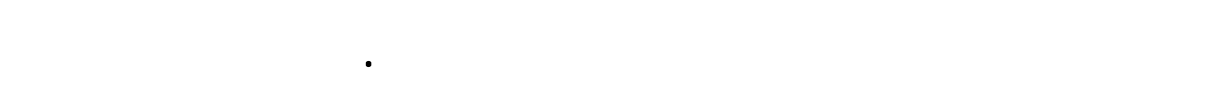

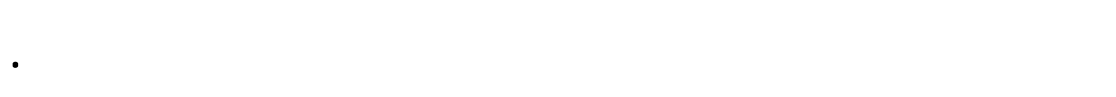

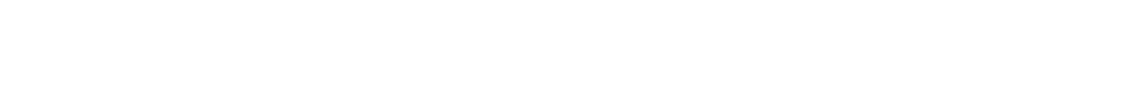




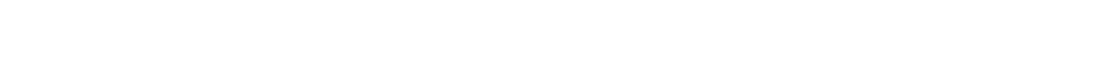

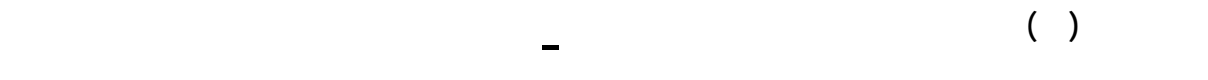

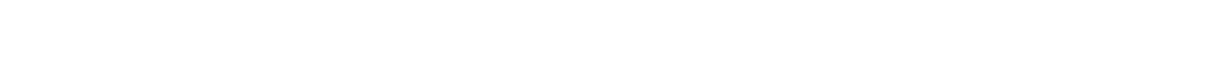

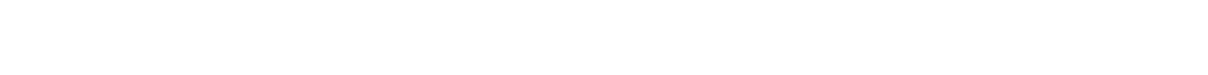

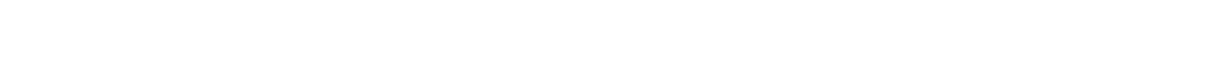

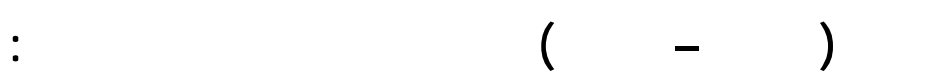

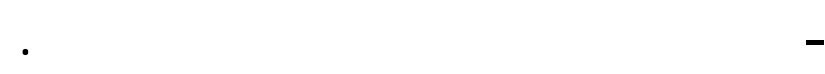

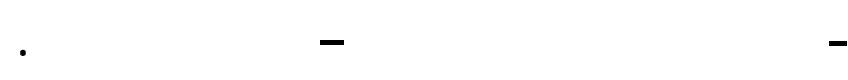

$$
\begin{aligned}
& \text { - المنف لهبلي. } \\
& \text { ثالثا: مشروعات مستقبلية(Tr) }
\end{aligned}
$$

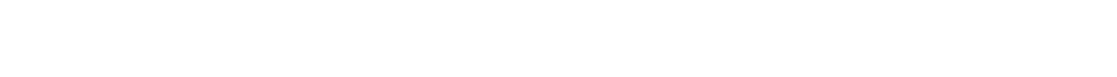

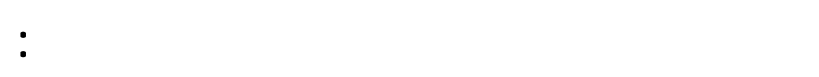

$$
\text { أ - قةتبيلت ديرسانت كلانهن. }
$$

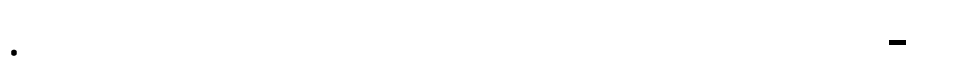

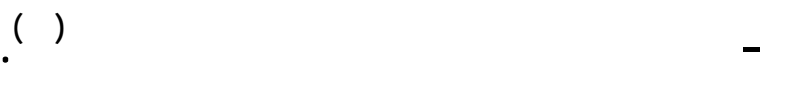

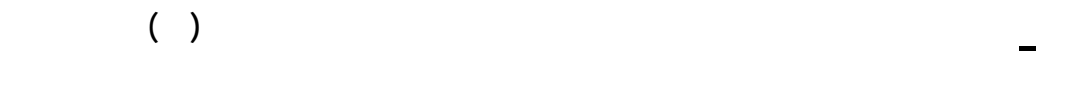

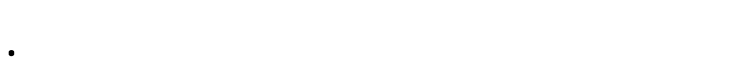

$$
\text { 0 - لوثلى الهة بلأديرة الهصرة. }
$$

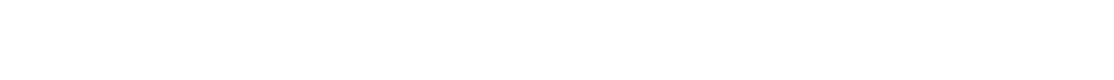




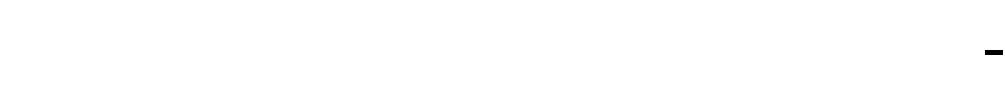

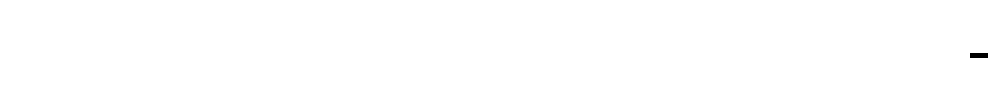

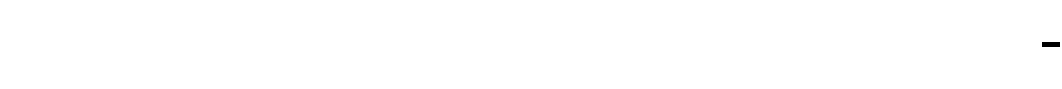

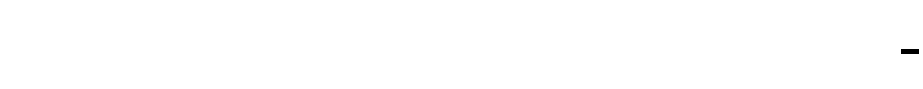

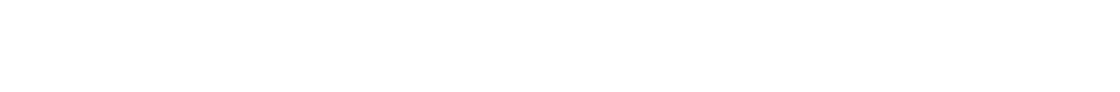

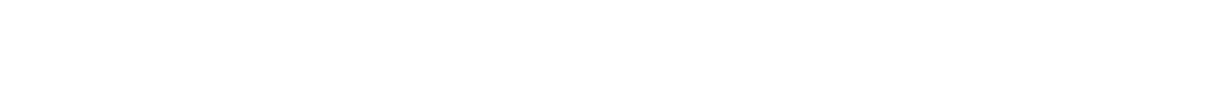

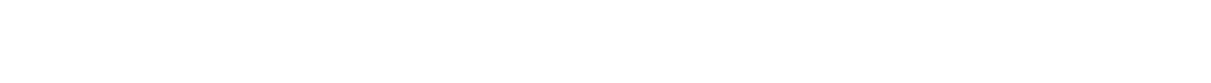

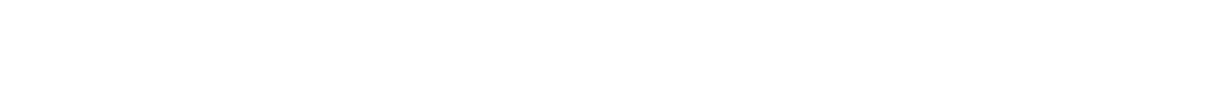

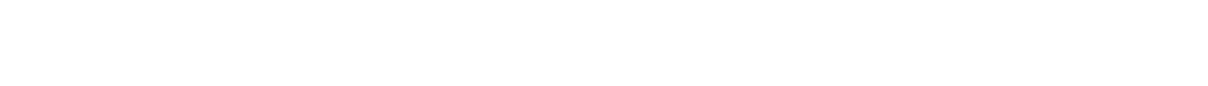

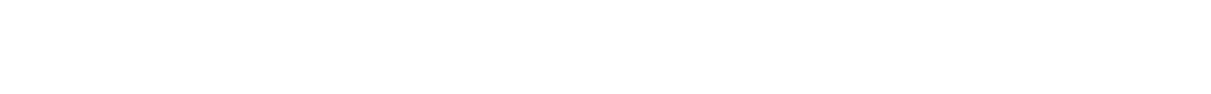

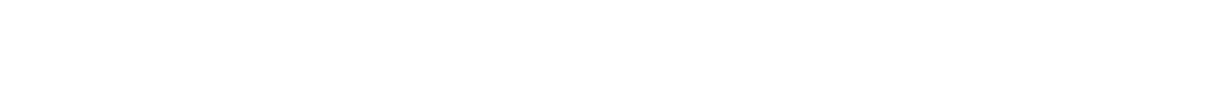

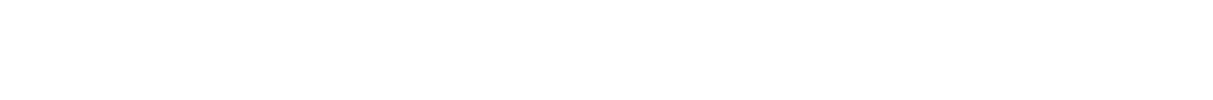

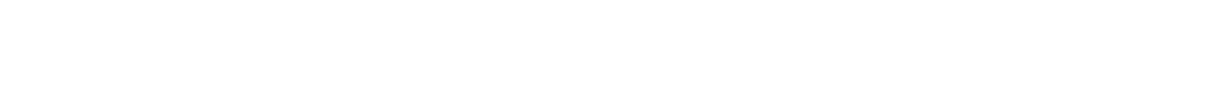

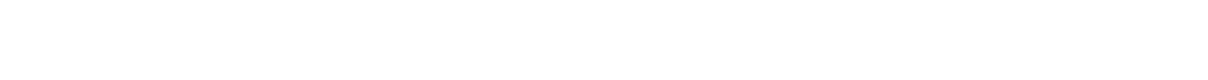

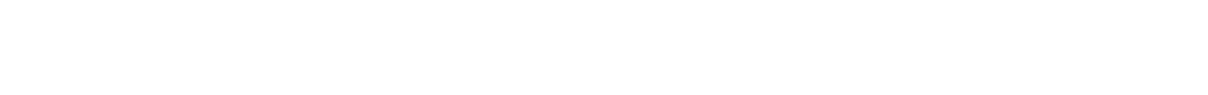

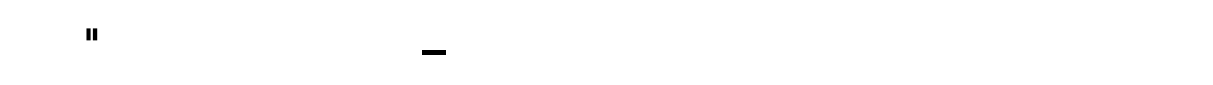

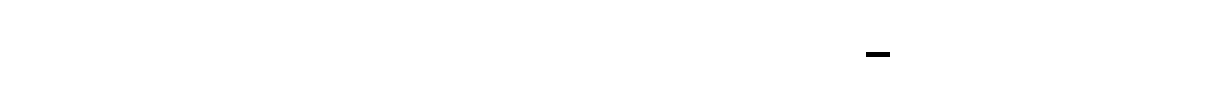

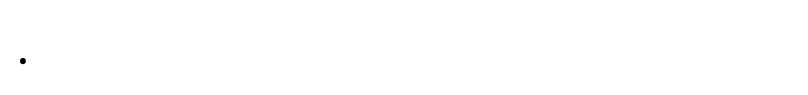

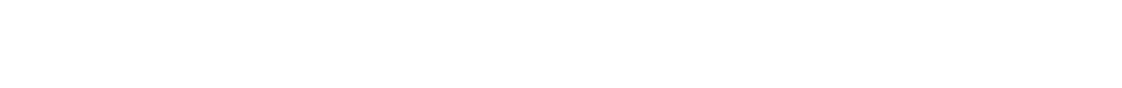

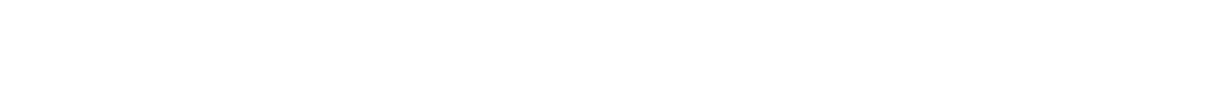

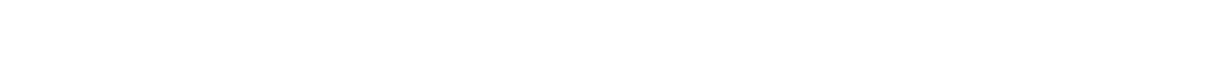

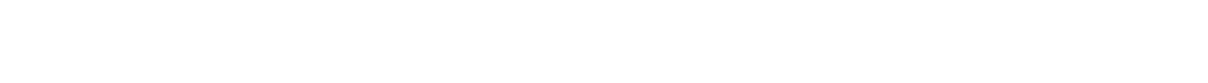




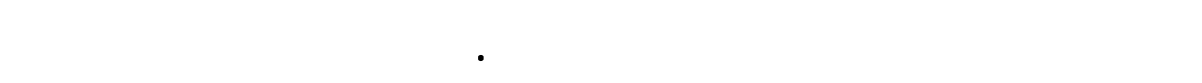

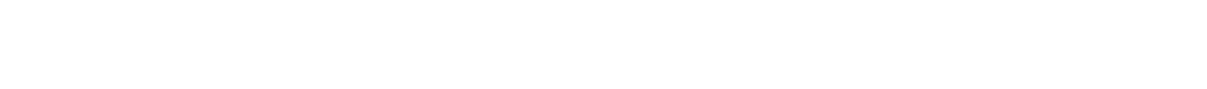
علل وش علل التنريب علي تالك الاستمارة.

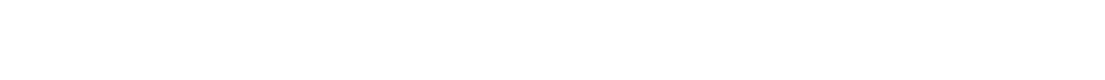

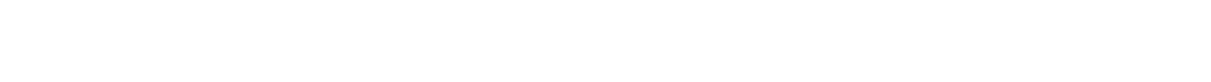

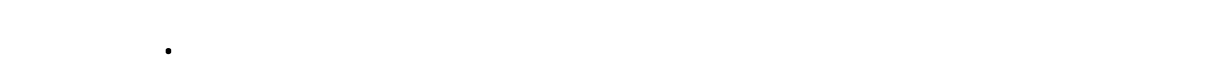

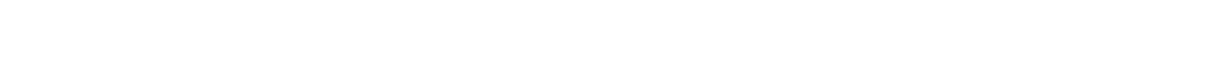

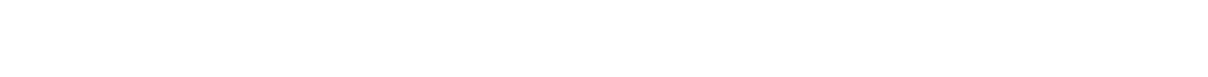

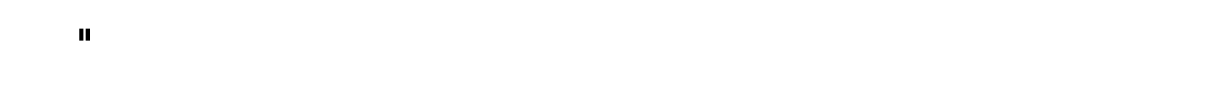

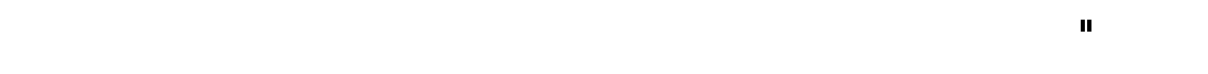

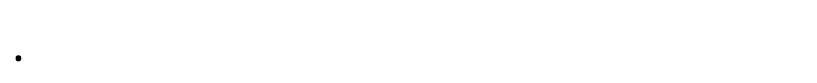

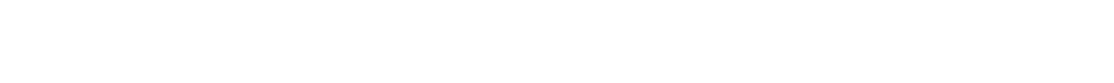

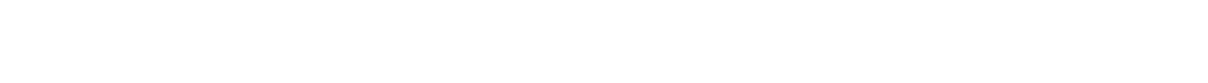

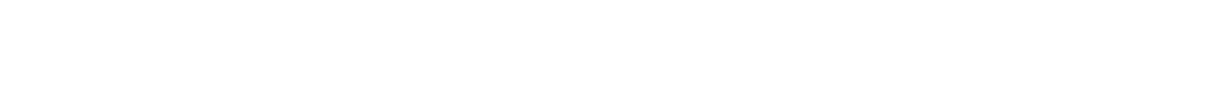

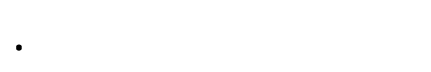

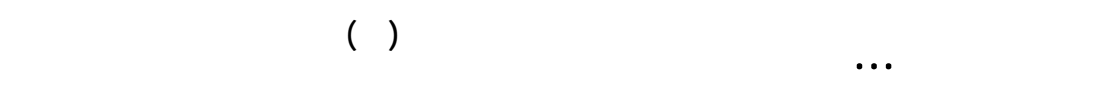

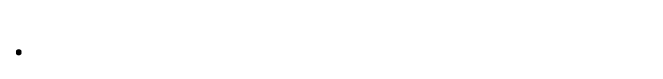

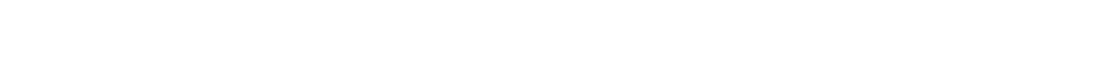

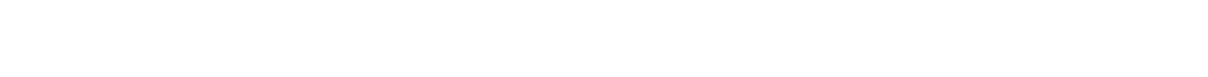

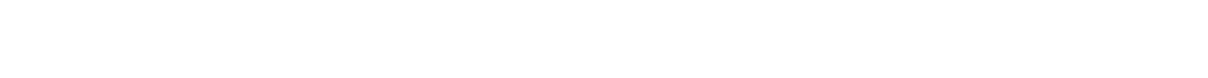

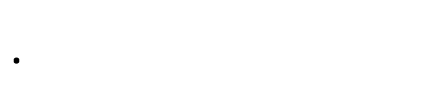




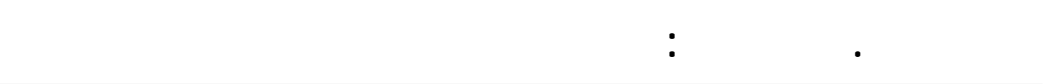

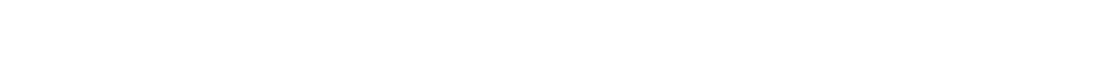

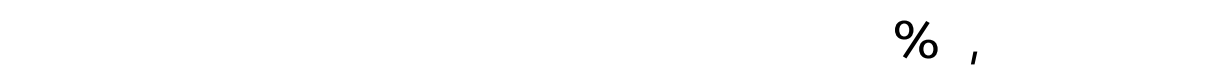


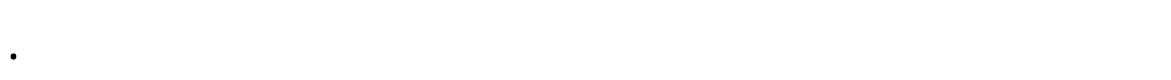

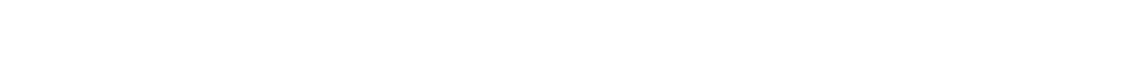

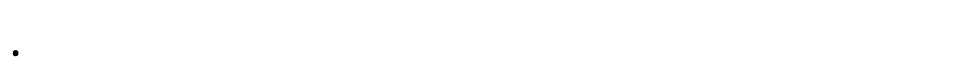

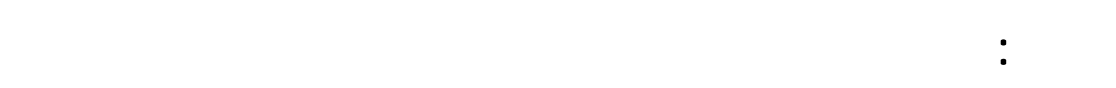

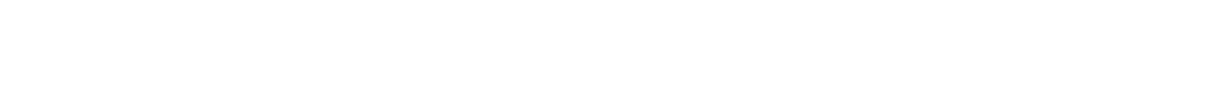

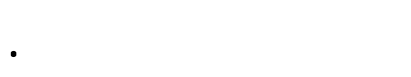

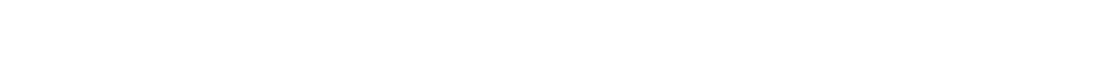

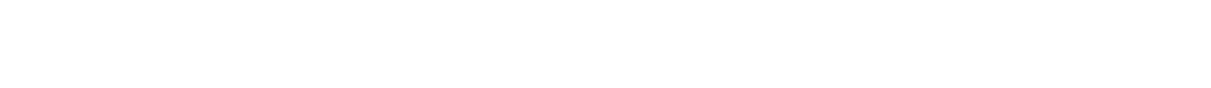

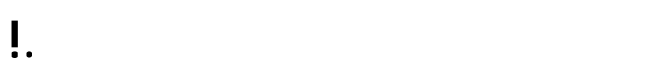

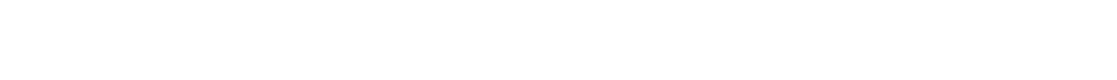

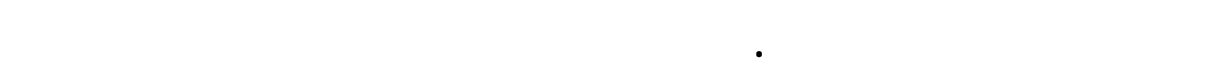

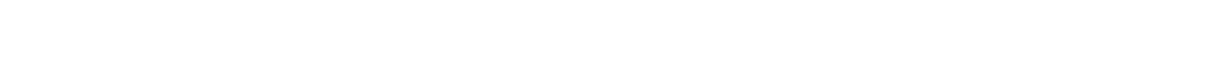

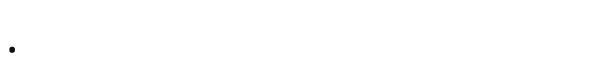


ह19

لروزلة (لمد لهليع - 11 - م)

هولث البهث:

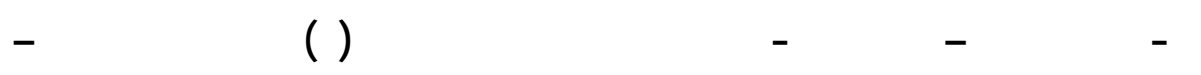

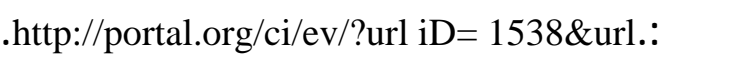

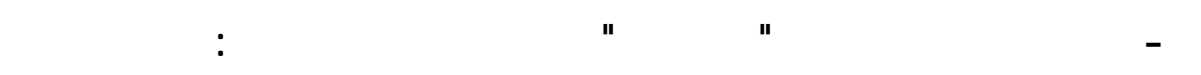

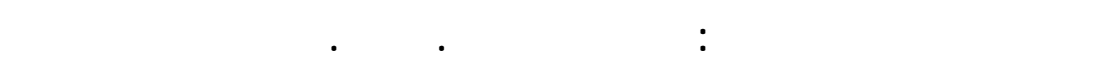

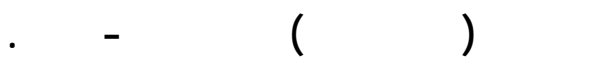

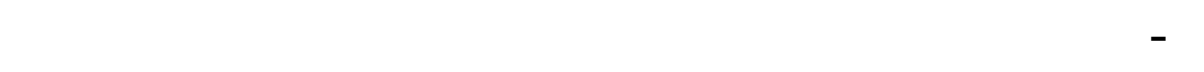

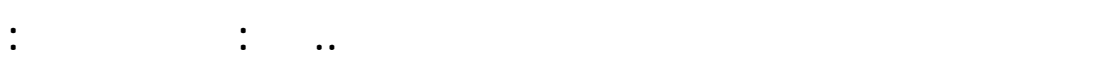

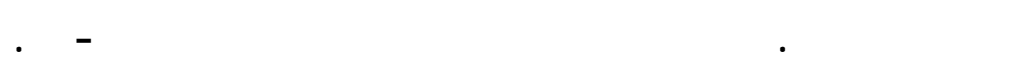

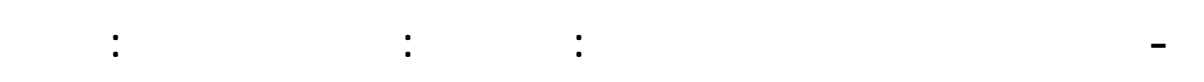

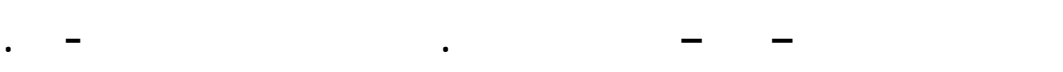

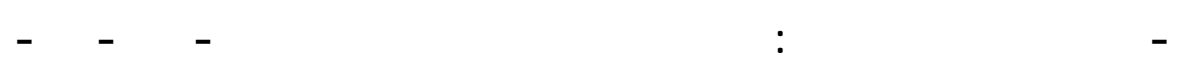

سنة عاعد الرئ.

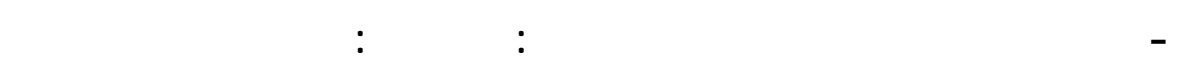

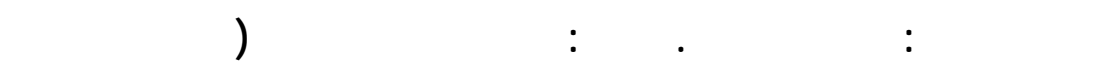

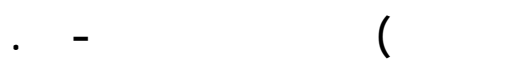

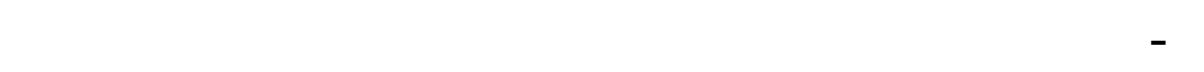

https.//j.mp/archives25.

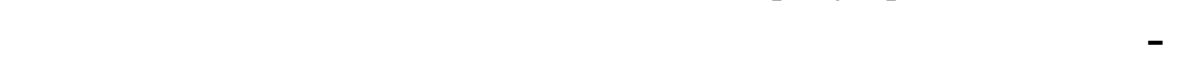

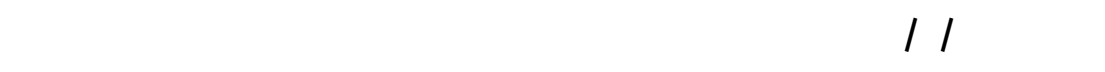

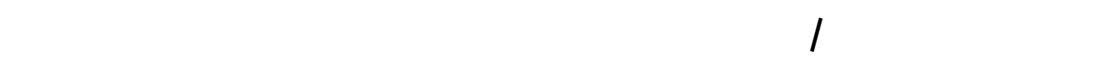

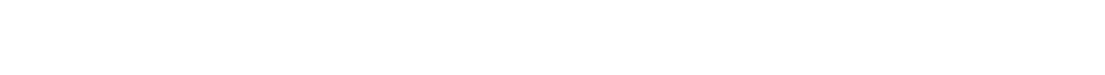

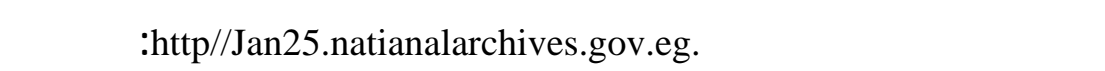

الموةقوالرهر القالتشكل رقم (1)

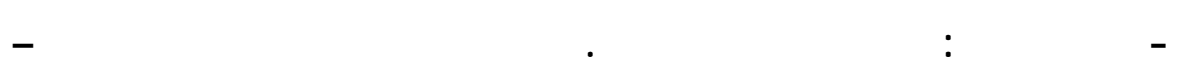

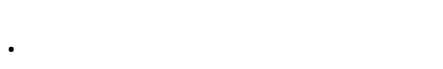




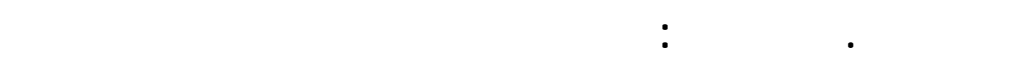

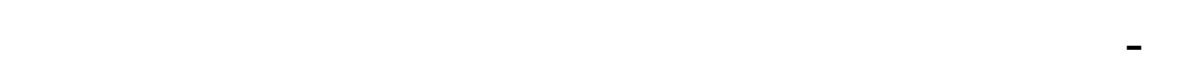

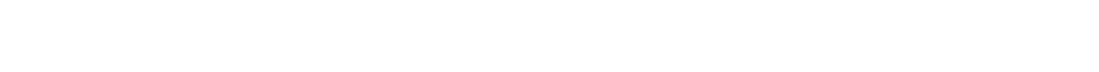

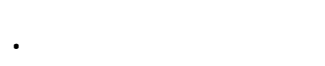

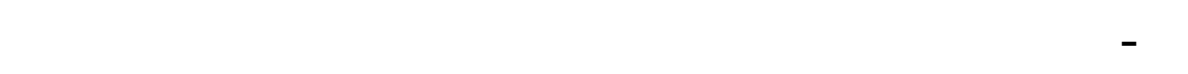

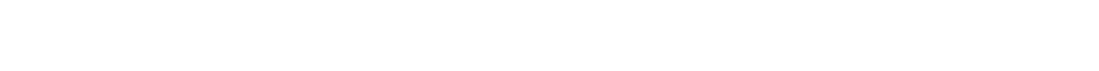

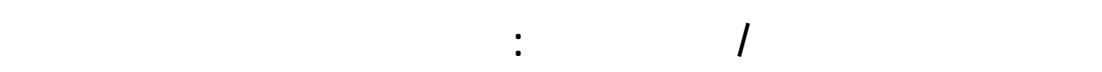

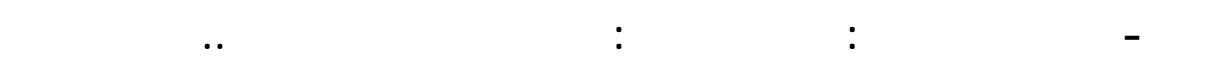

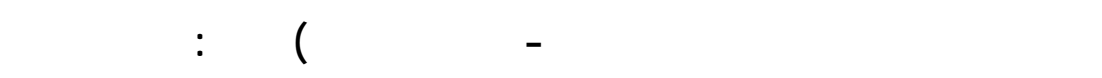

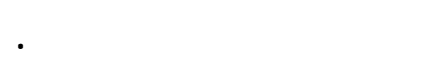

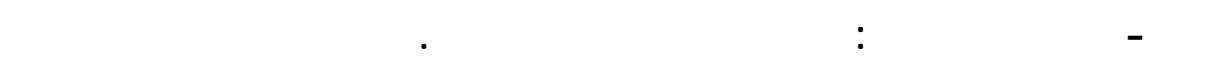

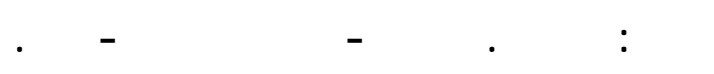

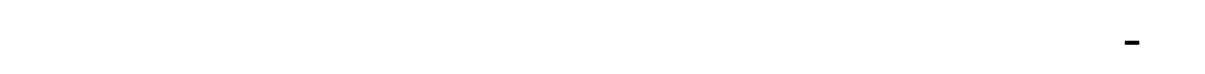

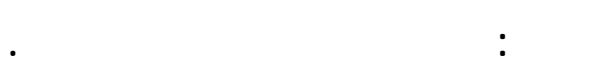

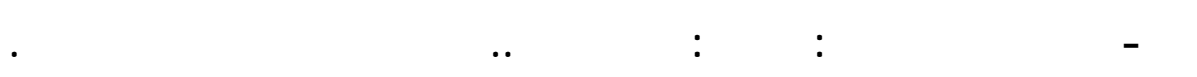

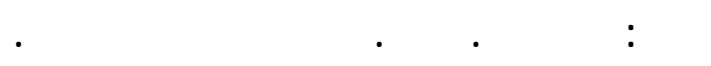

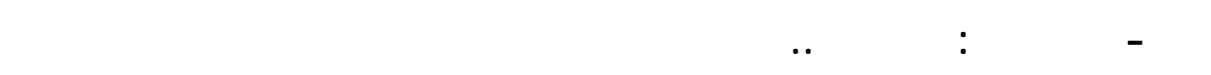

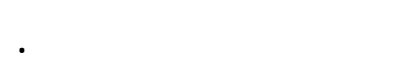

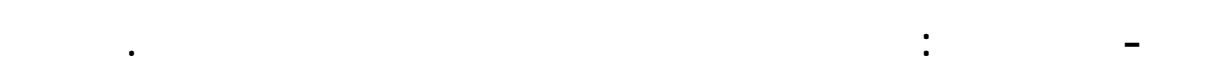

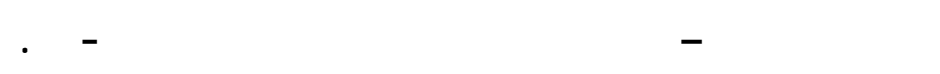

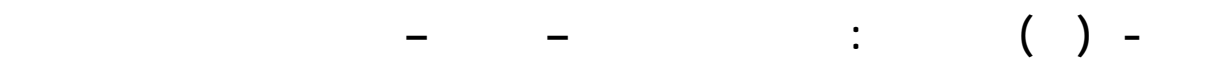

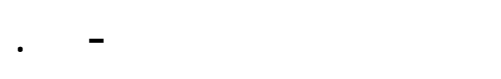

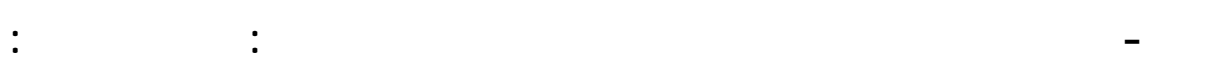

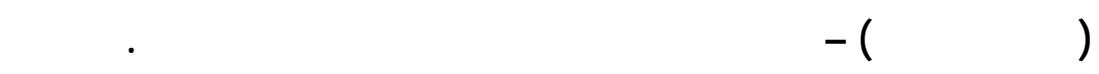
r r - 


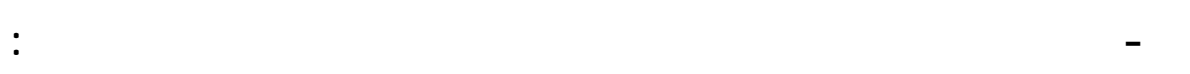
www.unesco.org/new/en/cutlural

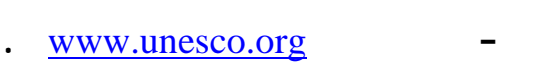

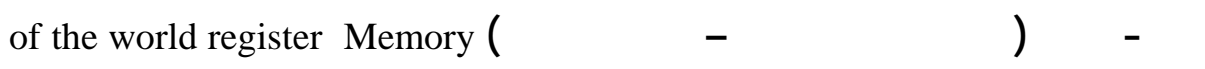
Monination form.

سד - الخارلمسمارة المونسكو - بند س، عشكل قفم r.

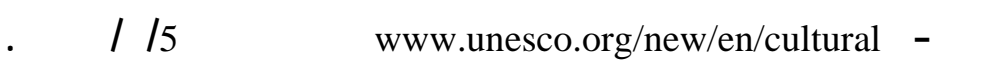

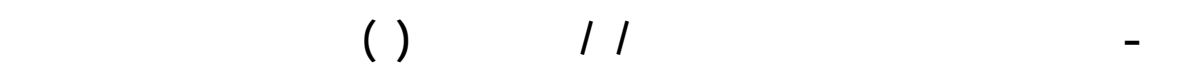

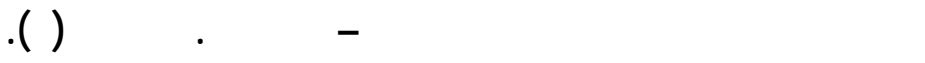

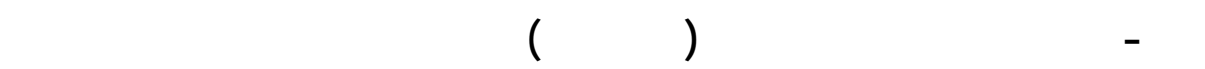

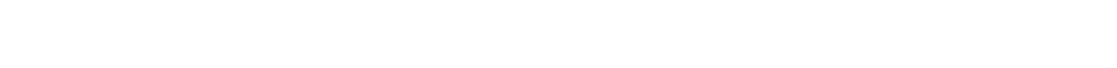

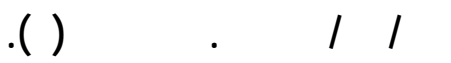

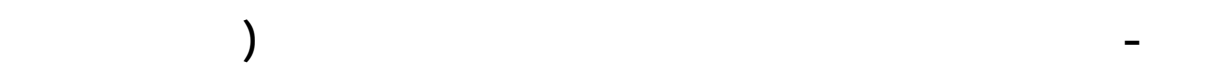

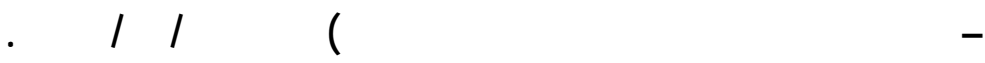

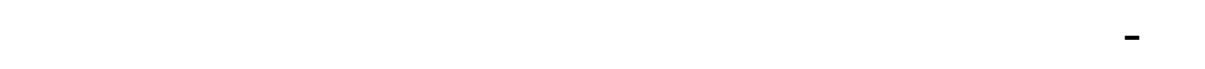

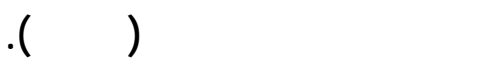

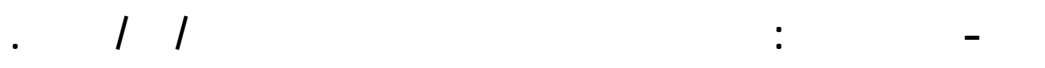

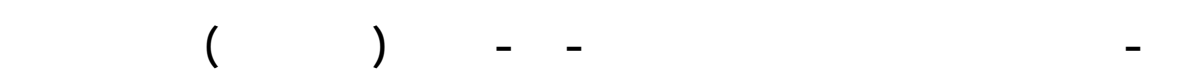

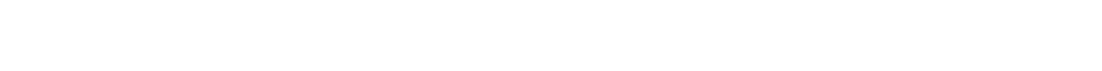
يتم إنبله.

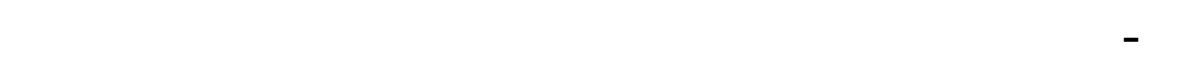

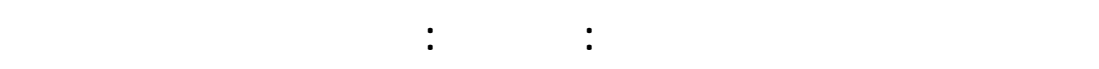

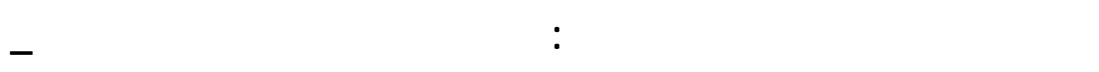

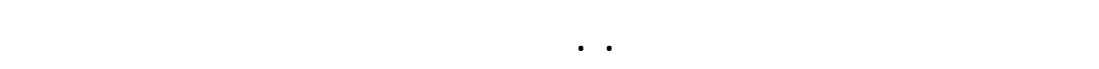

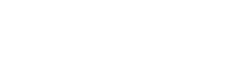

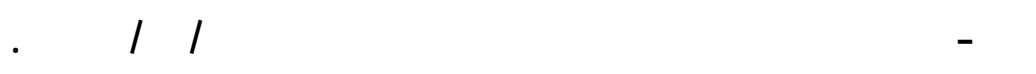




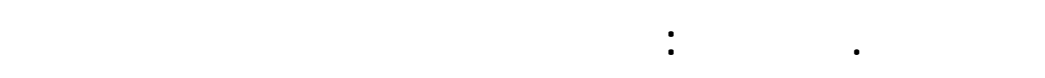

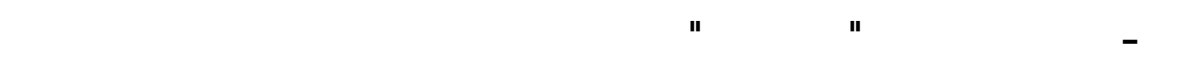

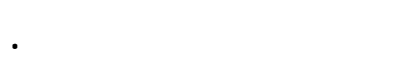

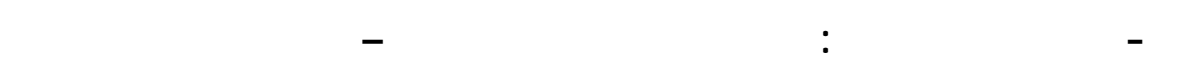

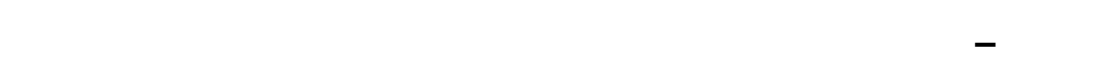

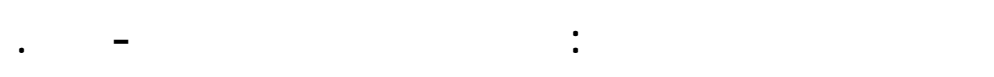

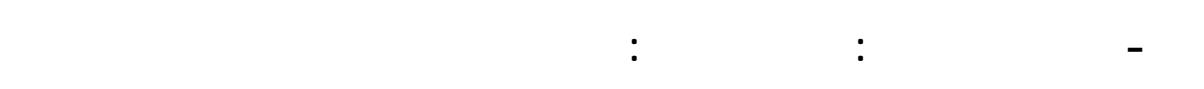

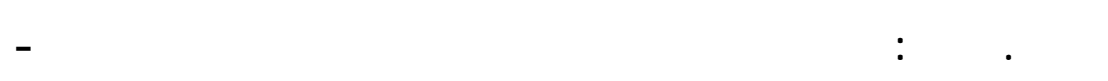

.10r 
$=\cdots$

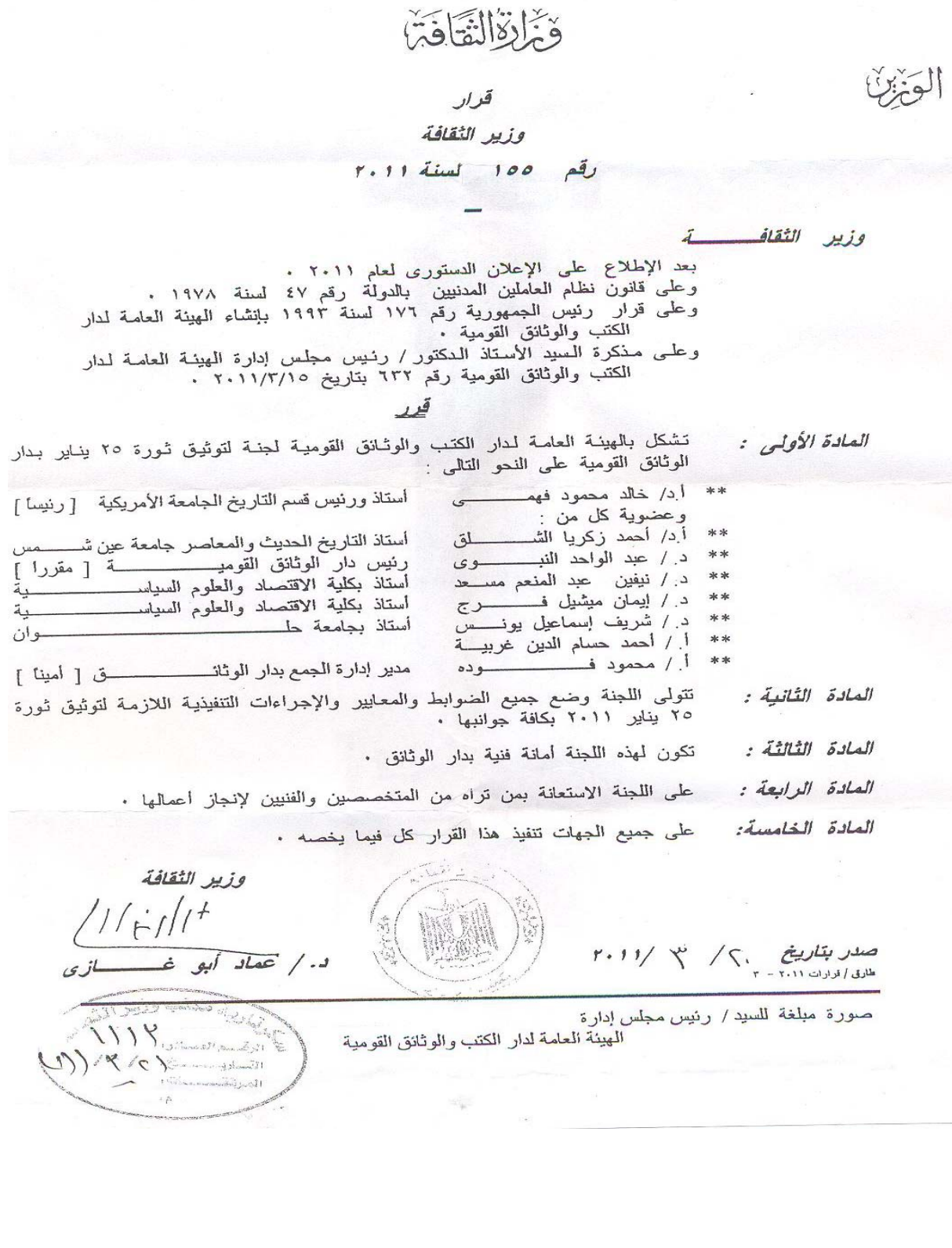




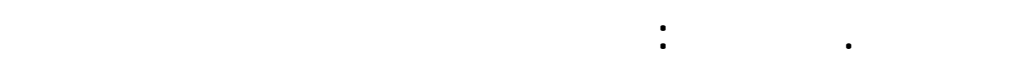

\section{MEMORY OF THE WORLD REGISTER}

NOMINATION FORM

\section{PART A - ESSENTIAL INFORMATION}

1 SUMMARY

Highlight the nature, uniqueness and significance of the nominated documentary heritage.

\section{DETAILS OF THE NOMINATOR}

$2.1 \quad$ Name (person or organisation)

2.2 Relationship to the documentary heritage nominated

2.3 Contact person (s)

2.4 Contact details (include address, phone, fax, email)

3 IDENTITY AND DESCRIPTION OF THE DOCUMENTARY HERITAGE

3.1. Name and identification details of the items being nominated

\subsection{Description}

Attach a description of the documentary heritage: refer to the guide for completing this form

\section{JUSTIFICATION FOR INCLUSION/ ASSESSMENT AGAINST CRITERIA}

Refer to section 4.2 of the General Guidelines for the selection criteria. If space insufficient, attach scparate sheets. Each question must be answered.

4.1 Is authenticity established? (see 4.2.3)

\section{شكلرقم

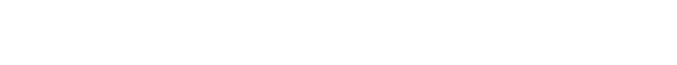




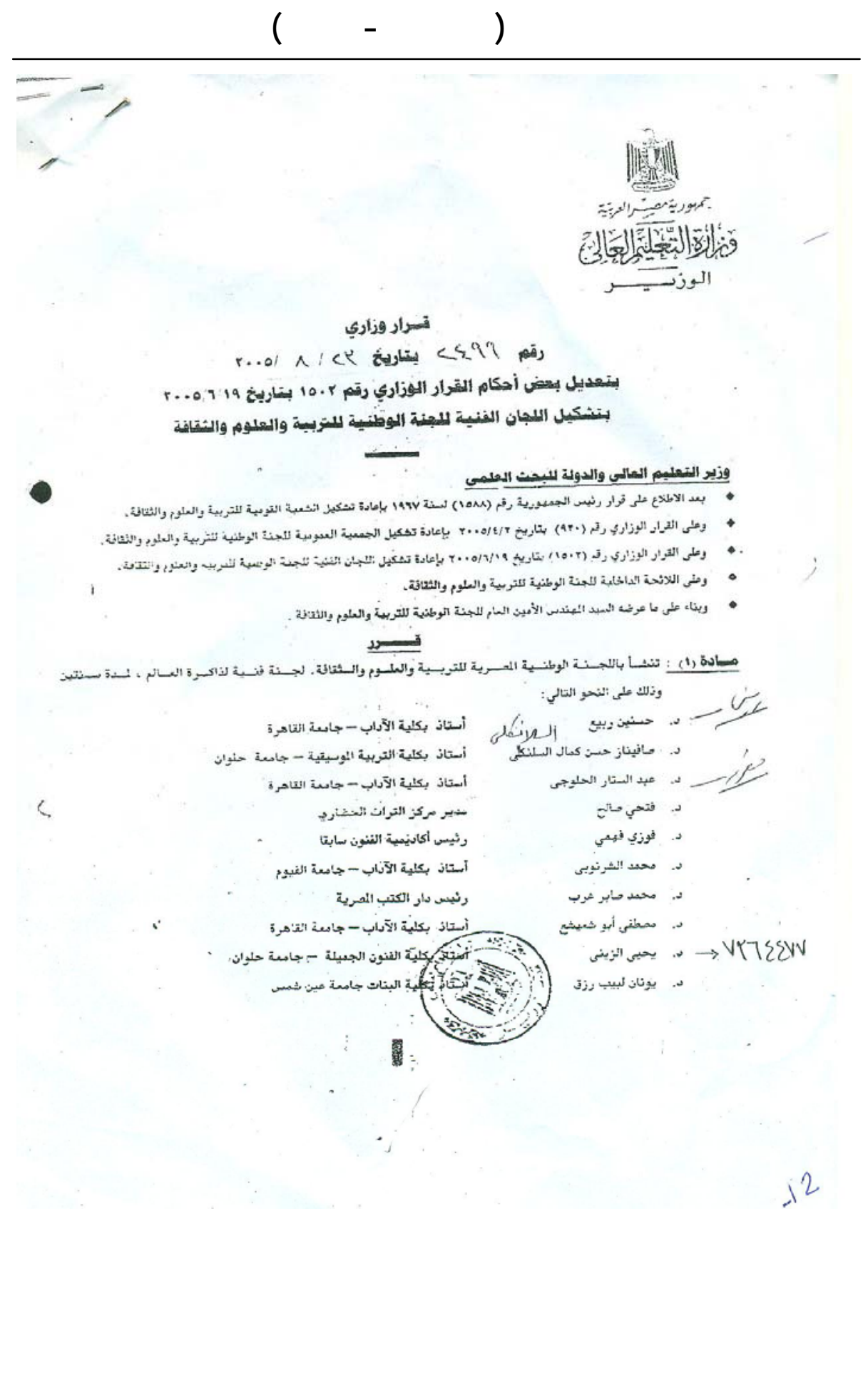




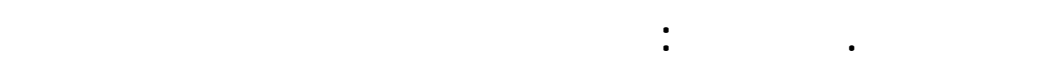

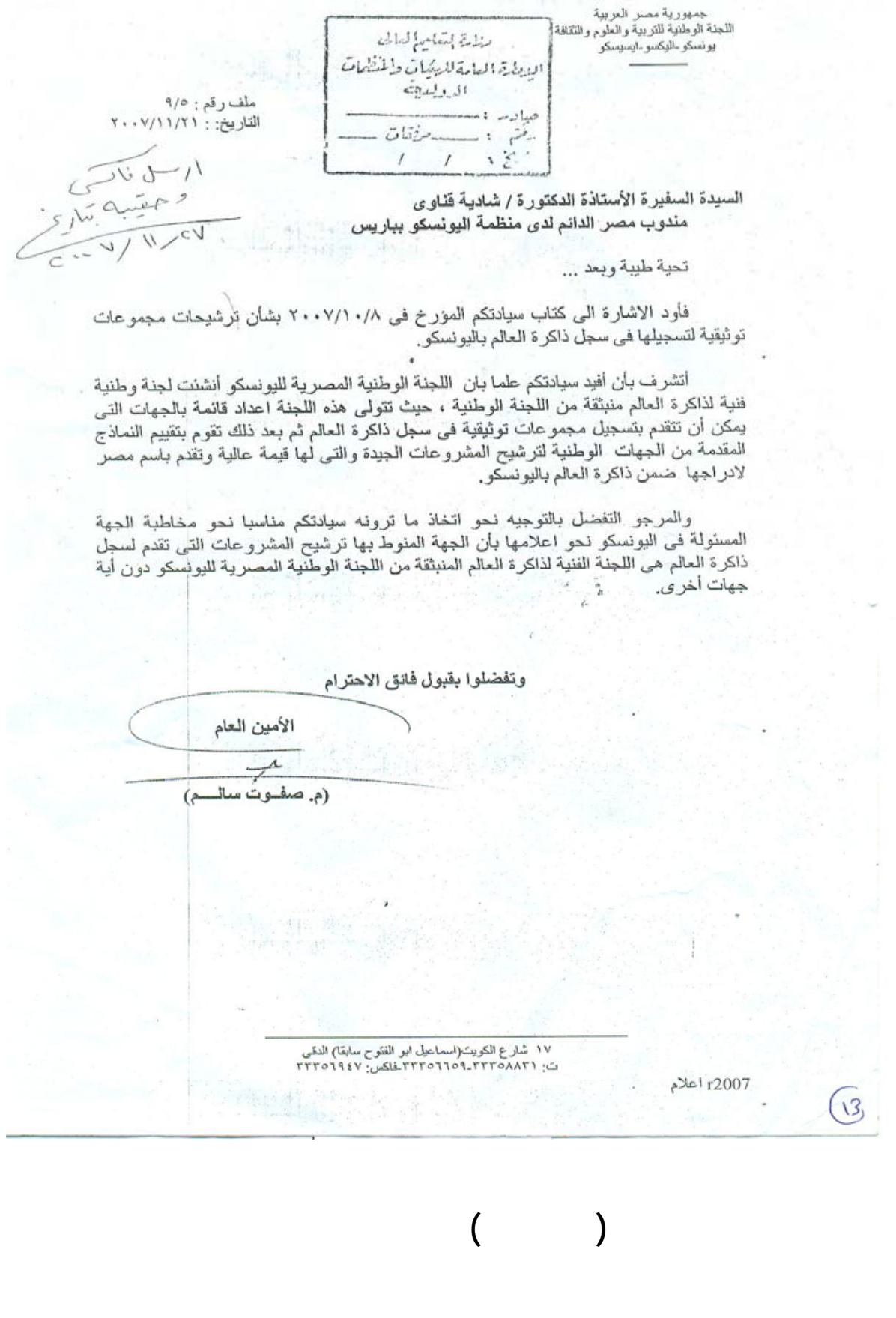


1. rue Miollis
75732 Paris cedex 15

Tel : $+33(0) 145681000$

Fax: $+33(0) 145671690$

Ref: CI/INF/ JS/05/96/1

CQN

The Assistant Director-General for

Communication and Information

Dear Prof. Morsi,

29 July 2005

is my pleasure to inform you that, upon the recommendation of the International Advisory Committee of the Memory of the World Programme, at its seventh meeting held in Lijang, People's Republic of China, from 13-17 June 2005, the Director-General has decided to include the:

\section{Deeds of Sultans and Princes}

in the "Memory of the World" Register.

To this effect, you will find enclosed herewith a certificate signed by the Director-General. The inclusion of this documentary heritage in the Memory of the World Register reflects its The inclusion of this documentary he protected for the benefit of all humanity. It also exceptional value and signifies that it should be protected for the benefit of all humanity. It also
offers an excellent opportunity for drawing attention to the importance of the collective memory and the need to safeguard it to enable as many people as possible to have access to it.

In this context, you may wish to celebrate its designation as part of the Memory of the World by affixing a plaque which could be unveiled at a special ceremony at the National Library \& Archives of Egypt or by organizing a commemorative event highlighting this item.

Yours sincerely,

Prof. Ahmed Morsi

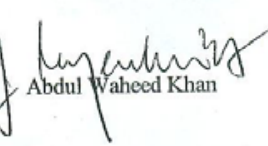

Chairman

The National Library \& Archives of Egypt

The Egyptian Ministry of Culture

Cornish El Nile- Ramlet Boulac

P.O.Box 11938

Cairo

Egypt

cc: Permanent Delegation of Egypt to UNESCO

Egyptian National Commission for UNESCO

UNESCO Office in Cairo

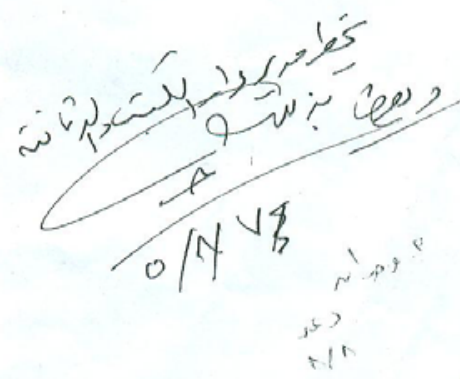

\section{شكلقفم 0}

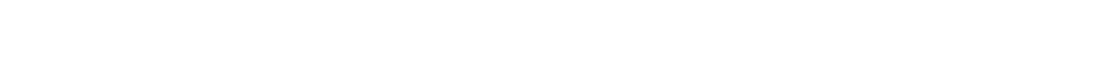




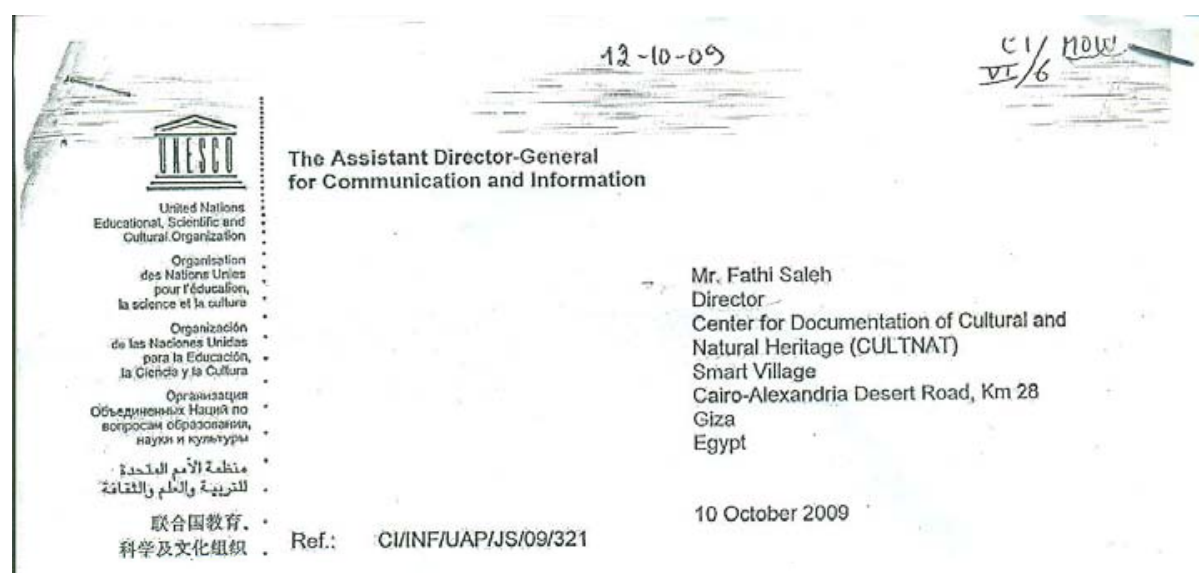

Subject: Memory of the World Register Nomination 2008-27

Dear Mr Saleh,

At its meeting held in Bridgetown. Barbados from 29 to 31 July 2009, the International Advisory Committee (IAC) of the Memory of the World Programme examined the following nomination which was proposed for inclusion in the Memory of the World Register:

Architectural Archive of the Royal and Public Buildings Authority

After a careful examination of the revised nomination, the International Advisory Committee concluded that the global influence of the item was- still not fully demonstrated although the nomination had been enhanced/ It noted although there was mention of the European and British influence in creating a truly Egyptian architectural style, the names of these architects and designers as wel as their nationalities are not listed/ Furthermore, it judged that since several developing and Arab countries were reported as sharing a similar experience in the outlook of their cities, this detracts from the claim of uniqueness.

However, the IAC felt that the nomination merited listing on a Regional register for the Arab States. It further suggested that efforts to make a clearer case for inscription on the International Register should be pursued.

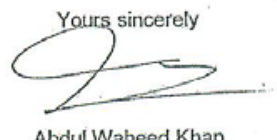

Abdul Waheed Khan

Cc: Egyptian National Commission for UNESCO Perman Permanent Delegation of Egypt to Ur ESCO Cairo

\section{شكل قفم 1}

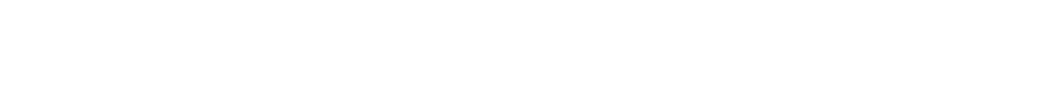

